\title{
NiMoAl catalysts derived from heptamolybdate-intercalated layered double hydroxides for hydrodeoxygenation of anisole
}

\author{
Chuang Li ${ }^{1}$, Xingzhao Zhang ${ }^{2}$, Xiao Chen ${ }^{1}$, Zhijian Peng ${ }^{2}$, Chi-Wing Tsang ${ }^{3}$ and Changhai Liang ${ }^{1 *}$ (D)
}

\begin{abstract}
The catalytic performance of NiMoAl catalysts derived from layered double hydroxide (LDH) precursors with molybdenum species incorporated into the interlayers was investigated for the hydrodeoxygenation (HDO) of anisole as a model compound of the lignin. The results showed that high dispersion of small Ni nanoparticles with $2-5 \mathrm{~nm}$ due to the pinning effect of $\mathrm{Mo}$ from $\mathrm{Mo}_{7} \mathrm{O}_{24}{ }^{6-}$ intercalated the $\mathrm{LDHs}$. Due to presence of the oxygen vacancy sites on the molybdenum oxide, the NiMoAl catalysts exhibit higher conversion of anisole than the corresponding NiAl catalyst. The activity for hydrodeoxygenation was enhanced with the increased content of molybdenum species, which can be attributed to the larger amount of acid sites-promoted removal of oxygen from anisole. In addition, the NiMoAl catalysts show higher resistance to deactivation than the NiAl catalyst, and can be broadly applied to other hydrodeoxygenation reactions.
\end{abstract}

Keywords: LDHs, Hydrodeoxygenation, Anisole, NiMoAl catalysts

\section{Introduction/background}

Due to the rapid depletion of petroleum resources and the ever-demanding needs for fossil fuels, exploration of renewable energy option as an alternative becomes inevitable. Lignocellulosic biomass is a kind of extensive, renewable and economical resources from agricultural and forest, and has attracted much attention [1, 2]. Nonetheless, the crude bio-oil produced derived from lignocellulosic biomass using conventional pyrolysis, gasification and liquefaction of lignocellulosic biomass contains large quantities of oxygenated compounds. Because of their chemical and thermal instability, low heating value, high viscosity and acidity that, to some degree, their applications in transportation have been limited [3, 4]. Fortunately, high quality liquid fuel can be obtained by catalytic hydrodeoxygenation, which is considered to be an exceedingly effective route for

\footnotetext{
* Correspondence: changhai@dlut.edu.cn

${ }^{1}$ State Key Laboratory of Fine Chemicals, Laboratory of Advanced Materials and Catalytic Engineering, School of Chemical Engineering, Dalian University of Technology, Dalian 116024, People's Republic of China

Full list of author information is available at the end of the article
}

bio-oils upgrading to valuable fuels with high energy density [5].

Hydrotalcite-like layered double hydroxide (LDH), a class of inorganic lamellar compounds having the general formula $\mathrm{M}^{2+}{ }_{1-\mathrm{x}} \mathrm{M}^{3+}{ }_{\mathrm{x}} \quad(\mathrm{OH})_{2}\left(\mathrm{~A}^{\mathrm{n}-} \mathrm{x} / \mathrm{n}\right) \cdot \mathrm{yH}_{2} \mathrm{O} \quad\left(\mathrm{A}^{\mathrm{n}-}=\right.$ anion with charge $\mathrm{n}$ ), has been found to be active and stable in a wide variety of catalytic applications, such as electrocatalysis [6], photocatalysis [7], $\mathrm{H}_{2}$ generation from water [8], $\mathrm{O}_{2}$ formation from water oxidation [9], and various chemical transformation of small organic and inorganic molecules [10], etc. Catalytic conversion of oxygenated bio-oil fraction using various oxygenated monomers or oligomers as the model compounds and the direct hydrodeoxygenation (HDO) of lignin had been extensively studied [11]. However, the use of LDH in the application of biomass-to-energy conversion has been very limited. Usually, noble metal catalysts have been widely used in the HDO of various oxygenated bio-oil monomers [12, 13]. However, the high cost of the catalysts limits their applications. As new hydrotreating catalysts, transition metal phosphides and carbides have been studied [14], in which the selectivity toward heteroatom removal have been kept 
improving. In addition, nickel-based catalysts seem to be a promising non-noble metal catalytic system for lignin-derived model compounds to produce fuel components because of the high HDO activity, sulfur-free nature and low cost, as have been demonstrated by our previous studies [15-18].

We have previously demonstrated an original method to obtain nickel-based catalysts deriving from layered double hydroxides (LDHs) precursors [19]. We have found that the hydrogenation capacity of these catalysts is stronger than the corresponding hydrogenolysis activity. However, the occurrence of agglomeration of $\mathrm{Ni}$ particles during the reaction easily leads to inactivity [19]. Recently, Aditya et al. [20] found that the modification of $\mathrm{Mo}_{2} \mathrm{C}$ surface by the oxygen-containing reactants promotes the selectivity towards benzene and toluene - the products of direct hydrodeoxygenation. Indeed, effective hydrodeoxygenation of biomass-derived oxygenate is achieved with $\mathrm{MoO}_{3}$ which produces unsaturated hydrocarbons with high yields under low $\mathrm{H}_{2}$ pressures [21]. Therefore, $\mathrm{MoO}_{3}$ is considered to be beneficial to the dispersion of active metal particles and the synergistic effects between them.

In this work, NiMoAl catalysts were prepared by calcination of NiAl-heptamolybdate LDHs derived from ion-exchange with ammonium heptamolybdate of NiAl-terephthalate LDHs. To understand the HDO performance of Mo modified Ni-based catalysts with different Mo content, anisole is used as a model compound since it has relatively simple molecular structure and high abundance of $\mathrm{C}_{\text {methyl }}-\mathrm{O}$ bonds and $\mathrm{C}_{\text {aromatic }}-\mathrm{O}$ bonds. The materials exhibited high HDO activity for the cleavage of anisole under the low hydrogen pressure. The reaction pathway of anisole was also investigated for these catalysts, in which the different reaction steps corresponding to the active sites of these catalysts were altered, compared with the non-modified ones. Finally, the stability of catalyst was preliminarily analyzed.

\section{Results \& discussions}

\section{Characterization of LDH precursor}

Figure 1a illustrates the changes of the XRD pattern from NiAl LDH to NiMo30Al LDH. The profile of NiAl LDH sample is typical of the terephthalate intercalated-LDHs. The three sharp peaks in the region of $5-20^{\circ}$ correspond to the (003), (006) and (009) planes of the NiAl LDH structure [22]. The distance between the brucite layers is equal to $14 \AA$, calculated from $2 \theta=6.3^{\circ}$ for the (003) reflection of NiAl $\mathrm{LDH}$; and the brucite layer thickness is $4.8 \AA$, calculated from $2 \theta=62^{\circ}$ for that of the (010) reflection, which an interlayer spacing of $9.2 \AA$ may be deduced, consistent with terephthalate anions installed perpendicularly into the gallery space of the layers [23] (the length of the terephthalate anion is ca. $9 \AA$ with vertical). This is strong evidence that hydrotalcite-like materials were indeed obtained. However, the intensity of the diffraction peaks is significantly decreased upon exchange with heptamolybdate. For the NiMo30Al LDH sample, weak peaks at $2 \theta$ angles of ca. $6.8^{\circ}$, $14.8^{\circ}$, and $22.0^{\circ}$ are observed, respectively corresponding to lattice plane (003), (006), and (009), whereas the position of the $(010)$ diffraction peak at ca. $62^{\circ}$ never changes. Accordingly, an interlayer distance is $12.1 \AA$ and a brucite layer thickness is $4.8 \AA$, the gallery width is ca. $7.3 \AA$. The heptamolybdate anion
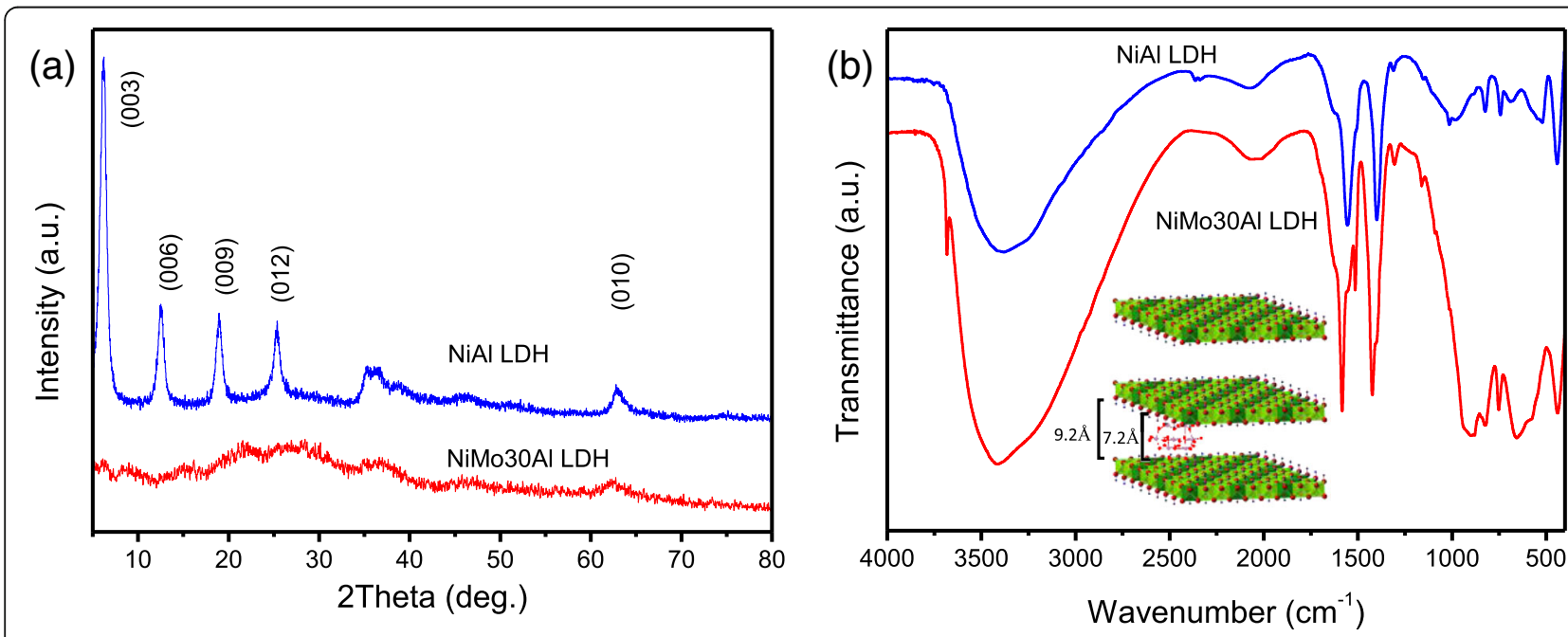

Fig. 1 (a) XRD pattern and (b) FTIR spectrum of NiAl LDH and NiMo30AI LDH samples 
oriented with $\mathrm{C} 2$ symmetry perpendicularly to the brucite layers is $7.2 \AA$, so the interplanar distances derived from the XRD patterns for NiMo30Al LDH are consistent with the intercalation of this anion. In addition, there are impure reflections, such as $\mathrm{Mo}_{2} \mathrm{O}_{7}{ }^{2-}$ anions in the heptamolybdate exchanged LDHs [24].

Figure $1 \mathrm{~b}$ shows the FTIR spectrum displaying the changes undergone by NiAl LDH upon ion-exchange with AHM, in the range $400-4000 \mathrm{~cm}^{-1}$. The broad absorption band in the region $3200-3600 \mathrm{~cm}^{-1}$ is assigned to the $\mathrm{OH}$ stretching vibrations, associated with the hydroxyl groups and interlayer water. In the wavenumbers range, NiAl LDH sample exhibits the narrow band at $1627 \mathrm{~cm}^{-1}$, which characterizes deformation of water molecules. The bands at 1390 and $1557 \mathrm{~cm}^{-1}$ are assigned respectively to the symmetric and anti-symmetric stretching vibrations of the carboxyl groups in the terephthalate anion. The characteristic bands of terephthalate anion are observed as a sharp peak at 749 and $835 \mathrm{~cm}^{-1}$. The band at $420-430 \mathrm{~cm}^{-1}$ is consistent with its assignment to $\mathrm{Ni}-\mathrm{O}$ stretching and the band at 531 $\mathrm{cm}^{-1}$, together with the one at $980-1020 \mathrm{~cm}^{-1}$ are consistent with their assignment to $\mathrm{Al}-\mathrm{O}$ stretching vibrations in octahedral $\mathrm{AlO}_{6}$ units [25]. For NiMo30Al LDH, the characteristic band of free $\mathrm{OH}$ group, $v(\mathrm{OH})$, is observed as a shoulder at $3635 \mathrm{~cm}^{-1}$, illustrating plenty of terephthalate anions are exchange with the smaller heptamolybdate ions thereby exposing hydroxyl compound in the interlay. The band near $940 \mathrm{~cm}^{-1}$ is assigned to $\mathrm{Mo}=\mathrm{O}$ bond stretching at terminal units and the ones near 885 and $645 \mathrm{~cm}^{-1}$ are attributed to the antisymmetric vibration modes of Mo-O-Mo units at the corners and edges of $\mathrm{MoO}_{6}$ octahedra respectively. Similarly, the heptamolybdate species are also octahedrally coordinated with oxygen [26].

The chemical analysis reveals that the content of $\mathrm{Ni}, \mathrm{Al}$, and $\mathrm{Mo}$ in the prepared precursors are almost close to the corresponding theoretical value, as presented in Table 1. This indicates the complete incorporation of heptamolybdate species into the gallery space. However, we notice it only when the amount of molybdenum is supersaturated that has been

Table 1 Elemental composition of intercalated-LDHs with different molybdenum incorporation

\begin{tabular}{lllll}
\hline Material & $\mathrm{Ni}^{[\mathrm{[a}]}(\mathrm{wt} . \%)$ & $\mathrm{Al}^{[\mathrm{a}]}(\mathrm{wt} . \%)$ & $\mathrm{Mo}^{[\mathrm{a}]}(\mathrm{wt} . \%)$ & $\mathrm{Ni} / \mathrm{Mo}^{[\mathrm{a}]}$ \\
\hline $\mathrm{NiAl} \mathrm{LDH}$ & 18.5 & 13.5 & - & - \\
$\mathrm{NiMO}_{5} \mathrm{Al}$ LDH & 18.3 & 13.2 & 5.2 & 5.8 \\
$\mathrm{NiMO}_{15} \mathrm{Al} \mathrm{LDH}$ & 16.5 & 11.6 & 14.9 & 1.8 \\
$\mathrm{NiMO}_{30} \mathrm{Al} \mathrm{LDH}$ & 14.4 & 10.9 & 32.9 & 0.7 \\
\hline
\end{tabular}

${ }^{[a]}$ the content of $\mathrm{Ni}, \mathrm{Al}$ and Mo determined by ICP-OES inferior to the theoretical value, which is due to some aluminum lixiviation during the ion-exchange [26].

\section{Characterization of NiMoAl catalysts}

The wide-angle XRD technique was performed to study the crystal phase change of heptamolybdate species with the increase of the calcination temperature for NiMo15Al sample, as shown in Fig. 2. When the calcination temperature is lower than $550^{\circ} \mathrm{C}$ under 33 vol.\% $\mathrm{O}_{2} / \mathrm{He}$ for $5 \mathrm{~h}$, there is only one strong reflection at $26^{\circ}$ attributed to the typical of $\beta$-nickel molybdate phase, where molybdenum is in tetrahedral coordination. When the NiMo15Al LDHs precursor is calcined at $850^{\circ} \mathrm{C}$, several peaks at $2 \theta$ of $23.3^{\circ}, 25.5^{\circ}, 26.6^{\circ}, 27.2^{\circ}, 27.5^{\circ}$, $32.1^{\circ}$, and $60.4^{\circ}$ appear respectively corresponding to lattice plane (02-1), (201), (220), (11-2), (20-2), (112) and (42-4) of nickel molybdate phase (JCPDS 45-0142) [27], indicating that molybdenum oxide species has been already transformed from amorphous to crystalline state with the increasing temperature. Some researchers found that different $\mathrm{O}$-coordinated MoAl compounds were formed on surface of alumina after calcination at certain temperature $\left(500-600^{\circ} \mathrm{C}\right)$, which leaded to the increase of Bronsted acid sites on the catalysts [28, 29]. Interestingly, no feature attributable to the presence of an aluminum-containing phase is observed in any of the XRD patterns [30].

The acidity of calcined catalysts derived from four LDHs precursors with different Mo content was determined by $\mathrm{NH}_{3}$-TPD, and the profiles are shown in Fig. 3. To compare the number of acid site, the integral area is converted into $\mathrm{NH}_{3}$ desorption amount (acidity, $\mu \mathrm{mol} / \mathrm{g}$ ). The number of total acid sites substantially increased from $304.7 \mu \mathrm{mol} / \mathrm{g}$ to $396.9 \mu \mathrm{mol} / \mathrm{g}$ as the Mo loading increased, which may be due to hydroxide groups bonded to $\mathrm{Mo}^{5+}$ species [31].

SEM images and corresponding X-ray maps of $\mathrm{Al}, \mathrm{Ni}$, $\mathrm{O}$, and $\mathrm{Mo}$ for $\mathrm{NiMo}_{15} \mathrm{Al}$ sample are presented in Fig. 4. It clearly showed that there are stack holes. In addition, the $\mathrm{Ni}, \mathrm{Al}$, and $\mathrm{Mo}$ atoms with high dispersion are grafted on the sample from X-ray mapping image, based on an in situ topotactic transformation of Mo-intercalated NiAl-LDHs precursors, which further indicated that Mo can be pinned between the Ni nanoparticles to prevent further sintering [32]. The presented guest-host mediated procedure is promising for the fabrication of metal NPs with a small size, high density, and good thermal stability for catalysis science.

Adsorption-desorption isotherms of $\mathrm{N}_{2}$ molecules provide quantitative information on the pore structure of all kinds of samples. The surface area, pore diameters, pore volumes, adsorption-desorption isotherms and pore size distributions (PSD) are listed in Table 2 and presented in Fig. 5. All the $\mathrm{NiMoAl}$ catalysts derived from Mo-intercalated LDHs 


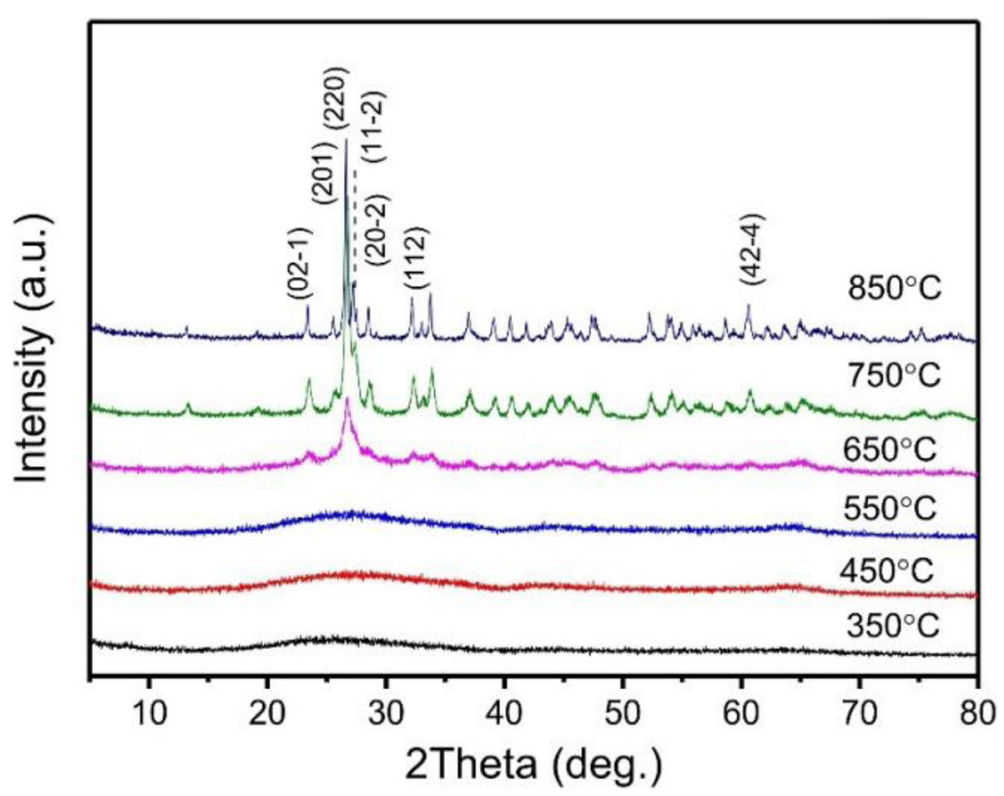

Fig. 2 XRD pattern of the NiMo15Al LDH sample after being calcined at different temperatures for $5 \mathrm{~h}$

precursors show a typical Type IV isotherm according to the IUPAC classification, which means a huge amount of mesoporous structure from the PSD. All samples have hysteresis loop because capillary condensation takes place, presenting the separation of the adsorption and desorption branches under a certain relative pressure range. However, there is no plateau next to the saturated state that match with the standard H4 type hysteresis loop. This clearly can be manifested that the pore structure is irregular, including slit pores, conical pores, interstices, and so on. In addition, the surface area and total pore volume gradually decrease with the increasing loading of molybdenum oxide, which is due to the pore blockage of molybdenum oxide. Nevertheless, the pore diameter remains a contrary tendency with the Mo content, which may be due to the supporting role of calcined heptamolybdate species in the porous materials.

$\mathrm{H}_{2}$-TPR profiles of the samples derived from the Mo-intercalated LDHs precursors with different Mo content are shown in Fig. 6, to understand the interaction among all components of the catalysts in the

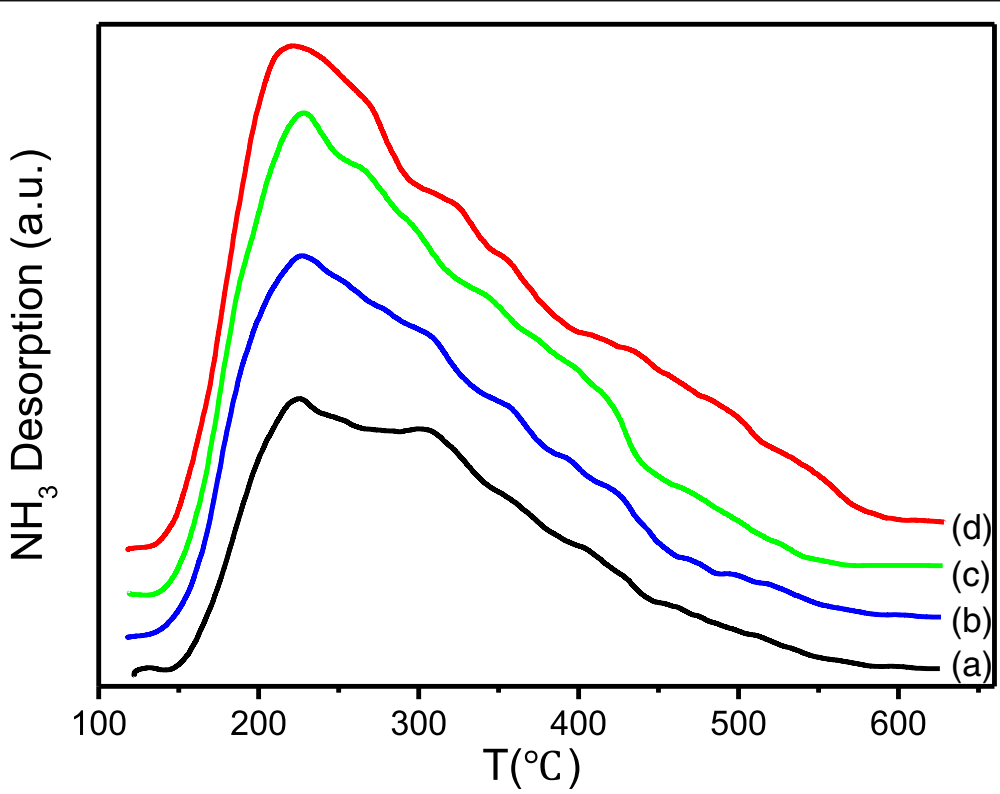

Fig. $3 \mathrm{NH}_{3}$-TPD profiles of (a) NiAl catalyst, (b) NiMo5Al catalyst, (c) NiMo15Al catalyst, (d) NiMo30Al catalyst 


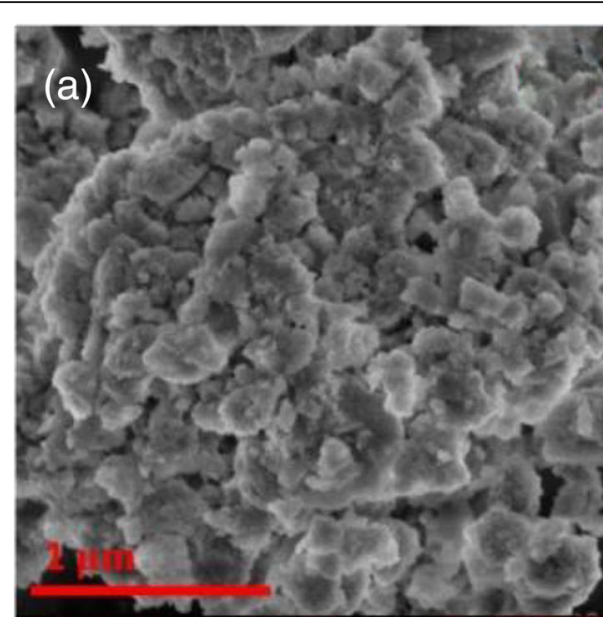

(c) (b)

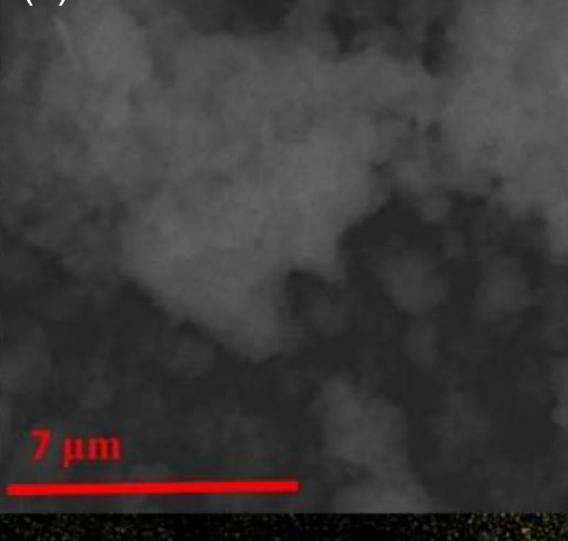

(d)

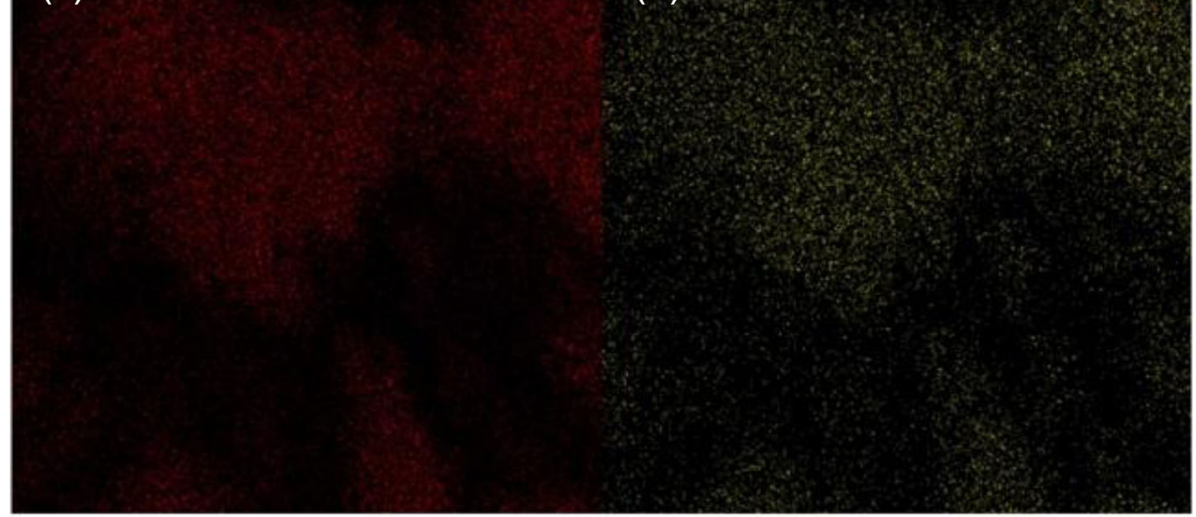

Al Ka1

Ni Ka1

(e)

(f)

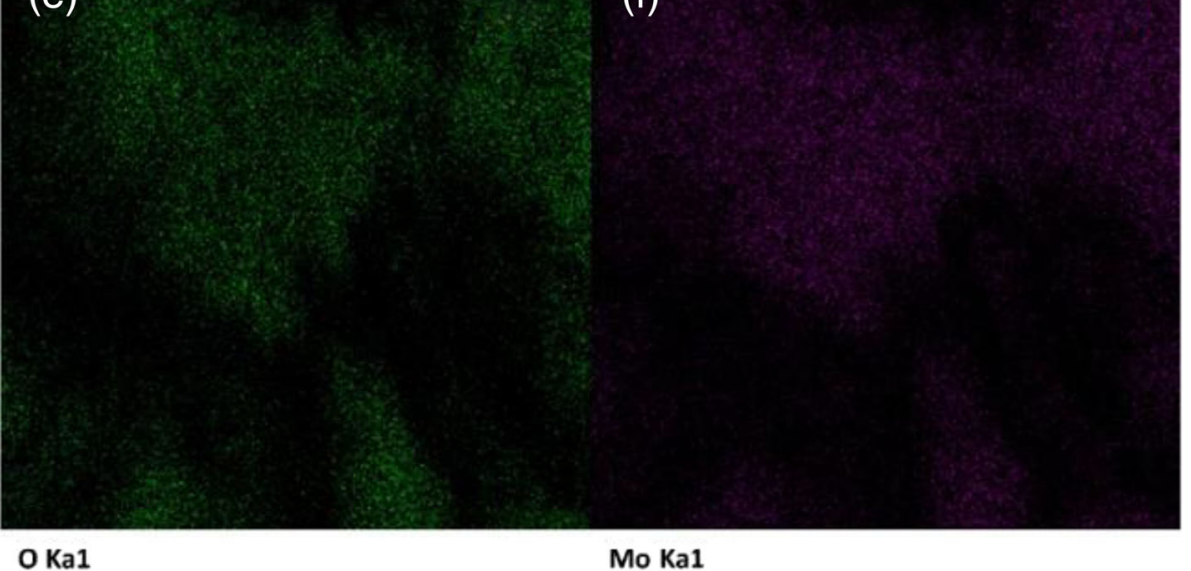

Fig. 4 SEM image and corresponding X-ray maps of Al, Ni, O and Mo for NiMo15Al samples

reduction process. The shoulder peak at $390^{\circ} \mathrm{C}$ is assigned to the reduction of $\mathrm{NiMoO}_{4}$ phase on the surface to $\mathrm{Ni}$ and $\mathrm{MoO}_{3}$ or the reduction of octahedrally coordinated nickel ions. The shapes are increasingly clear with the enhanced Mo content including the weak peak of the NiAl sample. It was found that the more nickel ions the much easier that the catalyst was to be reduced, suggesting that the spill-over hydrogen from the synergistic effects promotes the reduction of nickel ions [31]. The broad peak at $450^{\circ} \mathrm{C}$ is attributed to the reduction of tetrahedrally coordinated nickel ions. The peak at approximately $700{ }^{\circ} \mathrm{C}$ correspond to the 
Table 2 Structure properties of the NiMoAl catalysts

\begin{tabular}{lllll}
\hline Sample & $\mathrm{S}_{\mathrm{BET}}{ }^{[a]}\left(\mathrm{m}^{2} / \mathrm{g}\right)$ & $\mathrm{d}^{[a]}(\mathrm{nm})$ & $\mathrm{V}_{\text {total }^{\left[{ }^{[a]}\right.}\left(\mathrm{cm}^{3} / \mathrm{g}\right)}$ & $\mathrm{d}_{\text {TEM }}{ }^{[\mathrm{b}]}(\mathrm{nm})$ \\
\hline NiAl & 398 & 2.6 & 0.62 & 4.5 \\
NiMo5Al & 374 & 3.1 & 0.61 & 3.1 \\
NiMo15Al & 310 & 3.3 & 0.49 & 2.6 \\
NiMo30Al & 168 & 5.6 & 0.40 & 2.5 \\
\hline
\end{tabular}

[a] the BET surface area $\left(\mathrm{S}_{\mathrm{BET}}\right)$, average pore diameter $(\mathrm{d})$ and total pore volume $\left(\mathrm{V}_{\text {total }}\right)$ as determined by $\mathrm{N}_{2}$ adsorption-desorption isotherms at $-196^{\circ} \mathrm{C}$.

[b] the average particle size $\left(\mathrm{d}_{\text {TEM }}\right)$ obtained from TEM

reduction of $\mathrm{Mo}^{6+}$ in octahedral coordination to low-valence molybdenum cluster compounds [33], such as $\mathrm{Mo}^{5+}$ and $\mathrm{Mo}^{4+}$. The intensity enhanced with the increasing Mo content, probably as a result of the surface acidity number [34].

The surface structures of the NiMoAl catalysts are further investigated by XPS. Figure 7 shows the Mo 3d curve-fitted spectra for the reduced NiMoAl catalysts at $450{ }^{\circ} \mathrm{C}$ for $2 \mathrm{~h}$, and the binding energies and the atom distributions are summarized in Table 3. The signals are fitted into three sets of Mo 3d doublets, which respectively corresponded to the IV, V, and VI oxidation state. Some researchers [35-37] found that only after $500{ }^{\circ} \mathrm{C}$ reduction was $\mathrm{Mo}^{3+}$ obtained on the $\mathrm{Mo} / \gamma-\mathrm{Al}_{2} \mathrm{O}_{3}$ catalysts, indicating that no valence lower than $3+$ was obtained at the same reduction temperature. Based on these results, the reduction degree of molybdenum is strongly dependent on the acidity of the support. Therefore, the interaction between the metal and support would change the degree of reduction [38]. The BE value for $\mathrm{Mo}^{6+}$ is obtained from the XPS spectra (Mo $3 \mathrm{~d}_{5 / 2}$, $232.2 \mathrm{eV}$; Mo $3 \mathrm{~d}_{3 / 2}, 235.3 \mathrm{eV}$ ), a good agreement with the $\mathrm{BE}$ values observed in other literatures. For NiMoAl catalysts, the $\mathrm{BE}$ values of $\mathrm{Mo}^{5+}$ and $\mathrm{Mo}^{4+}$ vary constantly (Mo 3d $\mathrm{d}_{5 / 2}, 230.2 \mathrm{eV}$; Mo 3d $\mathrm{d}_{3 / 2}, 233.5 \mathrm{eV}$ for $\mathrm{Mo}^{5+}$ and Mo $3 \mathrm{~d}_{5 / 2}, 229.8 \mathrm{eV}$; Mo $3 \mathrm{~d}_{3 / 2}, 232.9 \mathrm{eV}$ for $\mathrm{Mo}^{4+}$ ). The relative concentrations of each Mo oxidation state are calculated by dividing the Mo $3 \mathrm{~d}$ area for a given oxidation state by the total area of the Mo $3 \mathrm{~d}$ envelope. The concentration of $\mathrm{Mo}^{6+}, \mathrm{Mo}^{5+}$, and $\mathrm{Mo}^{4+}$ species exhibited a significant change in the different catalysts.

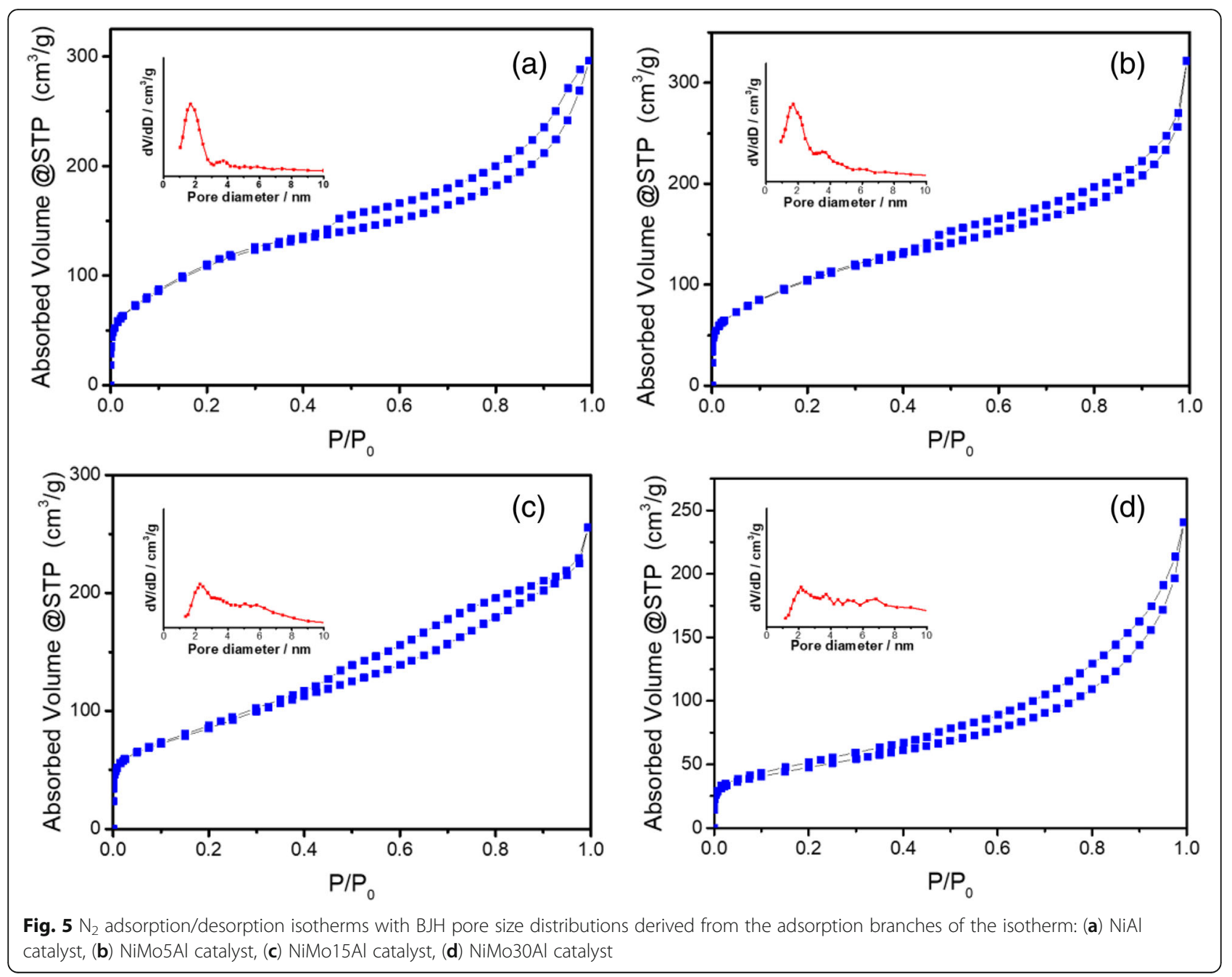




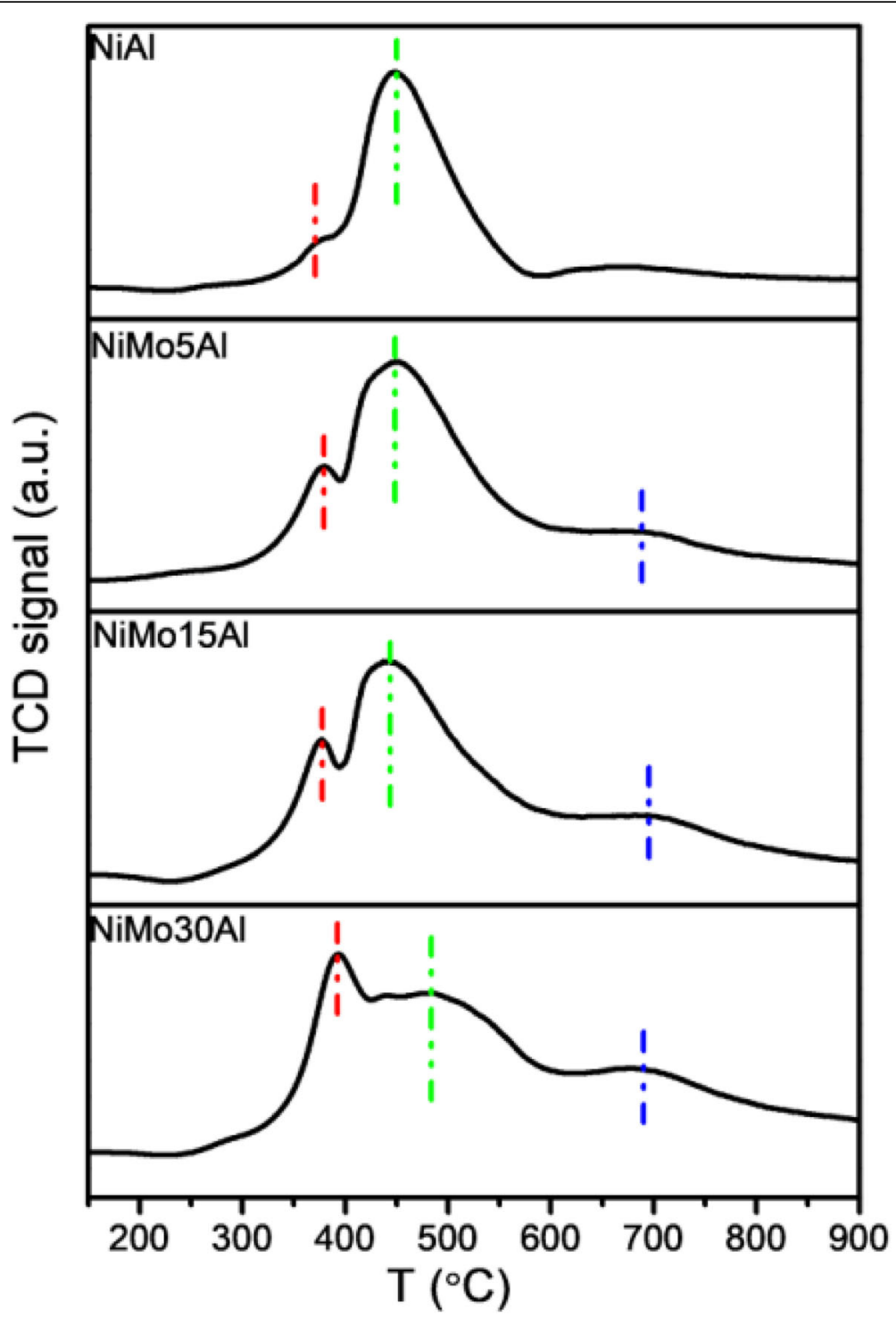

Fig. $6 \mathrm{H}_{2}$-TPR profiles of the NiMoAl catalysts with different Mo content after calcined in $\mathrm{Ar}$ at $400^{\circ} \mathrm{C}$
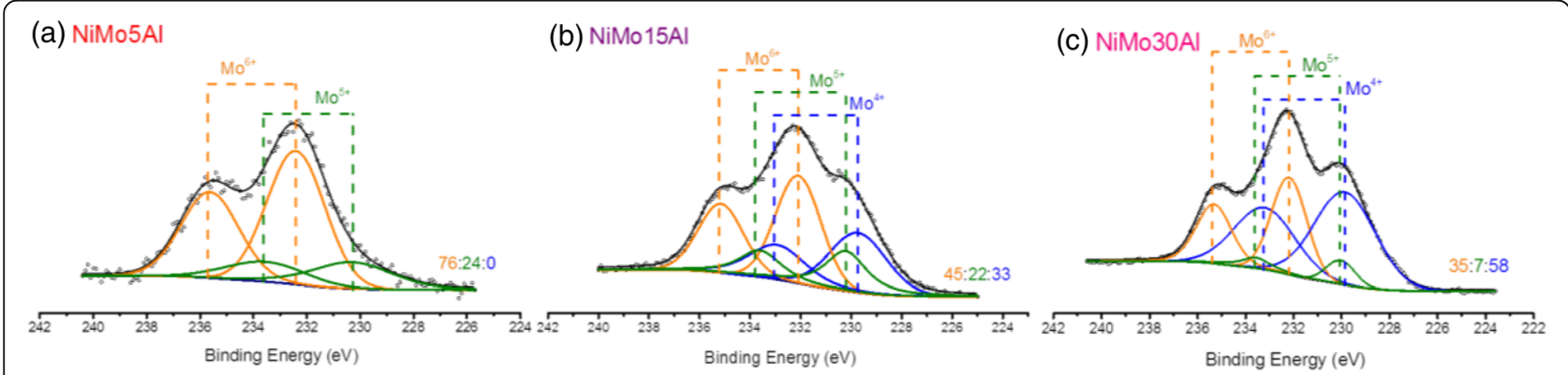

Fig. 7 XPS spectra of the Mo 3d region for the NiMoAl catalysts with different Mo content 
Table 3 Binding energy and distribution of molybdenum species on the reduced catalysts

\begin{tabular}{|c|c|c|c|c|c|c|}
\hline \multirow[t]{2}{*}{ Sample } & \multicolumn{3}{|c|}{ Binding energy ${ }^{[a]}(e V)$} & \multicolumn{3}{|c|}{ Concentration $^{[b]}(\%)$} \\
\hline & $\mathrm{Mo}^{6+}$ & $\mathrm{Mo}^{5+}$ & $\mathrm{Mo}^{4+}$ & $\mathrm{Mo}^{6+}$ & $\mathrm{Mo}^{5+}$ & $\mathrm{Mo}^{4+}$ \\
\hline NiMo5Al & 232.4 & 230.3 & - & 75.96 & 24.04 & 0 \\
\hline NiMo15Al & 232.1 & 230.21 & 229.74 & 45.50 & 21.75 & 32.75 \\
\hline NiMo30Al & 232.19 & 230.04 & 229.87 & 34.95 & 7.02 & 58.03 \\
\hline
\end{tabular}

The percentage of $\mathrm{Mo}^{4+}$ exhibited a steady increase from 0 to $58 \%$ with increasing Mo content, whereas that of $\mathrm{Mo}^{5+}$ and $\mathrm{Mo}^{6+}$ dropped from an initial high value of 76 to $35 \%$ and 24 to $7 \%$, respectively. These result indicate that a higher Mo content favors the formation of a lower valence of $\mathrm{Mo}^{4+}$ and $\mathrm{Mo}^{5+}$, suggesting that a higher reduction degree was obtained and more coordinately unsaturated sites are generated [31].
The XPS spectra for Ni 2p are shown in Fig. 8. Due to the multiple and overlapped peaks, the spectrum is also deconvoluted into two peaks, in which the first one at $852.5 \mathrm{eV}$ is due to the binding energy of $\mathrm{Ni} 2 \mathrm{p}_{3 / 2}$ and the latter at $858.8 \mathrm{eV}$ is assigned to that of $\mathrm{Ni}^{2+} 2 \mathrm{p}_{3 / 2}$. After reduction, the zero valent nickel is observed in each case [39], indicating that the nickel oxide on the surface of catalysts are mostly reduced even when the molybdenum oxide is not added, which correlates well with the $\mathrm{H}_{2}$-TPR results.

Transmission electron microscopy is conducted to understand the morphology and particle size distribution of these four catalysts. Figure 9 displays their typical TEM images of the well dispersed Ni nanoparticles produced from $\mathrm{Mo}_{7} \mathrm{O}_{24}{ }^{6-}$ intercalated NiAl-LDHs together with the distribution histograms of $\mathrm{Ni}$ particle size. The results reveal the homogeneous distribution of active species on the support can be obtained by calcination (a) $\mathrm{NiAl}$
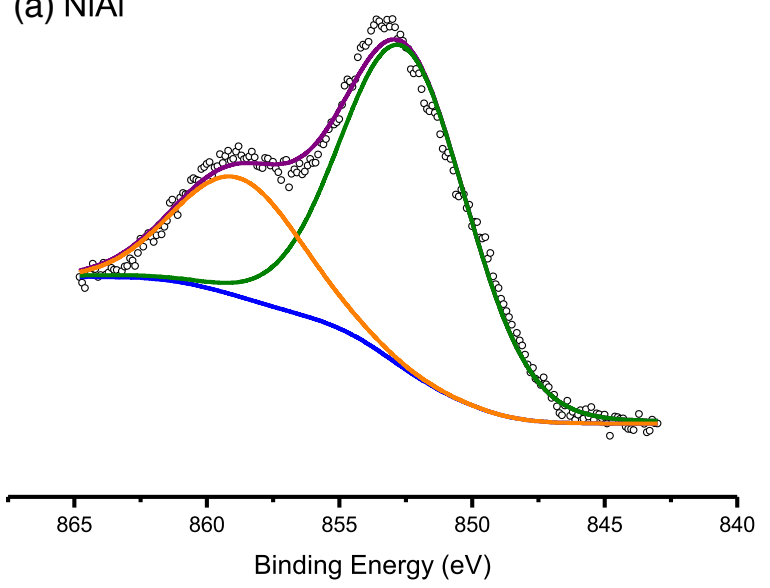

(c) NiMo15Al
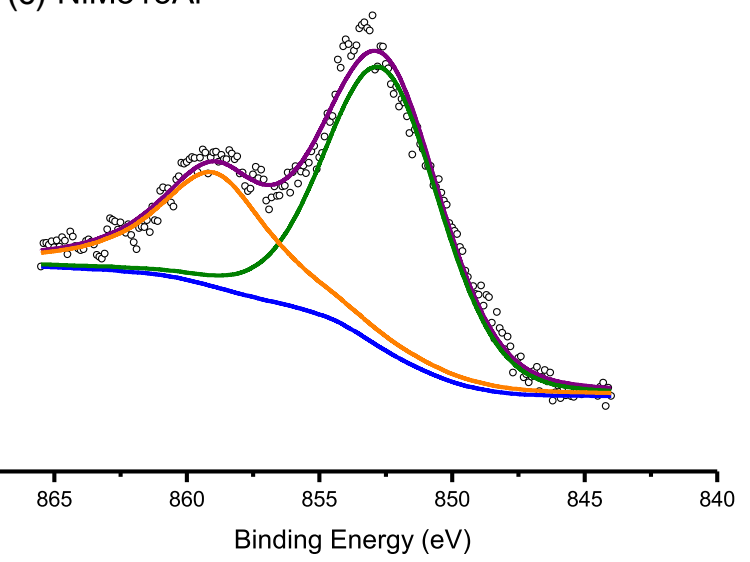

(b) NiMo5Al
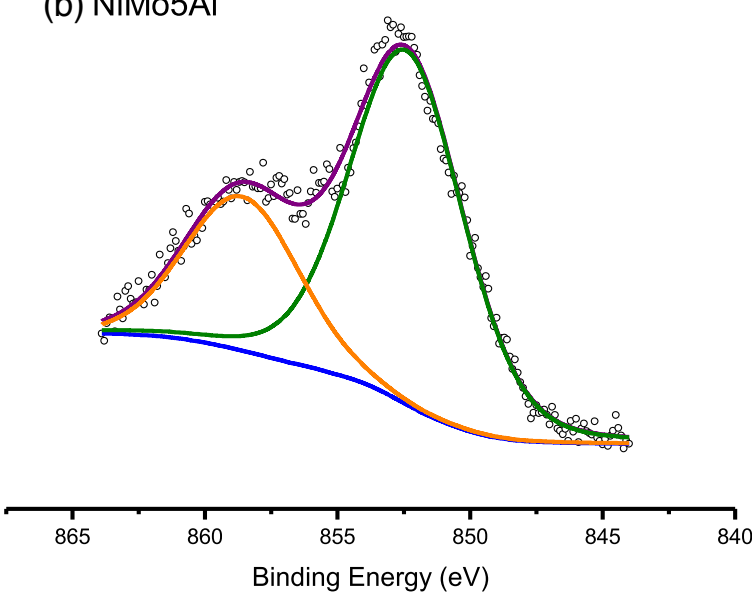

(d) NiMo30Al
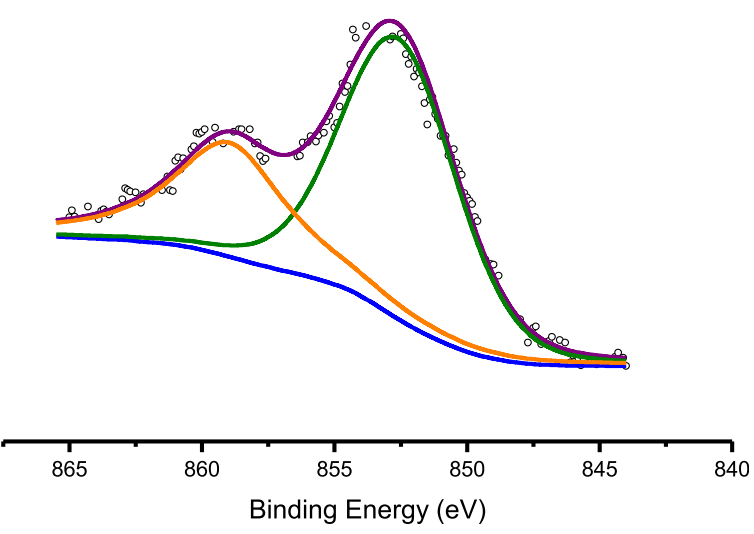

Fig. 8 XPS spectra of the Ni $2 p$ region for the NiMoAl catalysts with different Mo content 


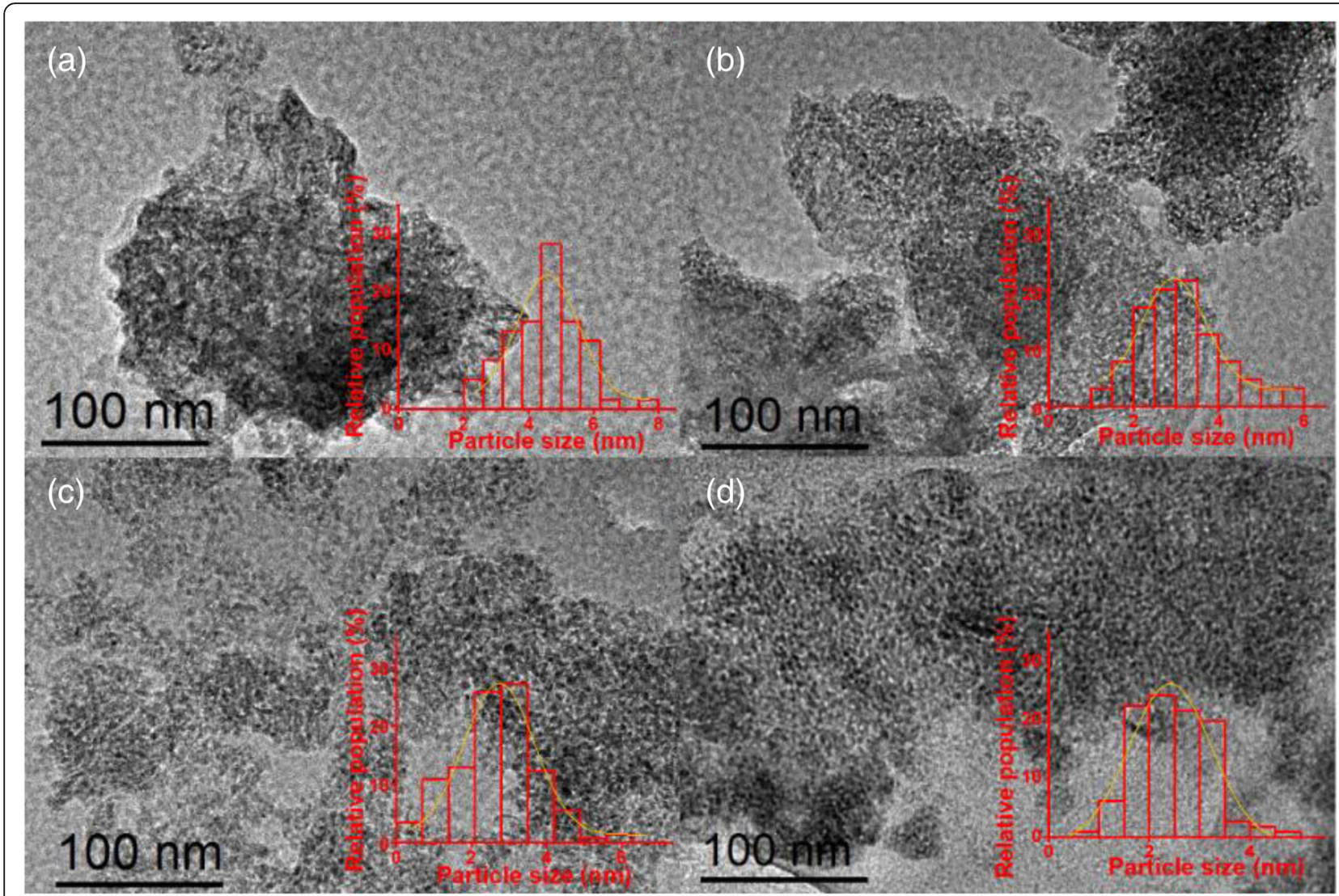

Fig. 9 TEM images of the reduced (a) NiAl catalyst, (b) NiMo5Al catalyst, (c) NiMo15Al catalyst, (d) NiMo30Al catalyst and the distribution of the Ni nanoparticles

and subsequent reduction of the LDH precursors. The catalysts present the lamellar structure formed by the LDHs, which provides the surface for the uniform distribution of metal catalyst. With the introduction of $\mathrm{H}_{2}$, neighboring $\mathrm{Ni}$ atoms rapidly form Ni nanoparticles. Sintering is prevented because $\mathrm{Ni}$ atoms in different layers would have to migrate over the interlayer spaces to sinter [32]. The average size of the particles calculated by statistical analysis on about 200 particles. The particle sizes of $\mathrm{NiAl}, \mathrm{NiMo} 5 \mathrm{Al}, \mathrm{NiMo15Al}$ and NiMo30Al are $4.5 \pm 0.7$, $3.1 \pm 1.0,2.6 \pm 1.1$, and $2.5 \pm 1.1 \mathrm{~nm}$, respectively. When the $\mathrm{C}_{8} \mathrm{H}_{4} \mathrm{O}_{4}{ }^{2-}$ anions are replaced with $\mathrm{Mo}_{7} \mathrm{O}_{24}{ }^{6-}$ anions by guest-host chemistry, well dispersed $\mathrm{Ni}$ nanoparticles with small sizes are obtained. In addition, the trend of $\mathrm{d}_{\mathrm{NiAl}}>\mathrm{d}_{\mathrm{NiMo5Al}}>\mathrm{d}_{\mathrm{NiMo15Al}}>\mathrm{d}_{\mathrm{NiMo30Al}}$ is likely due to the existence of Mo component pinned around the Ni nanoparticles, which exhibits strong interaction with the support to prevent effectively sintering.

Figure 10 displays the HRTEM image of NiMo15Al catalyst after reduction treatment in pure $\mathrm{H}_{2}(40 \mathrm{~mL} / \mathrm{min})$ at $450{ }^{\circ} \mathrm{C}$ for $2 \mathrm{~h}$. There are rare crystalline $\mathrm{MoO}_{3}$ particles and well-dispersed $\mathrm{Ni}$ nanoparticles with $2 \mathrm{~nm}$ anchored

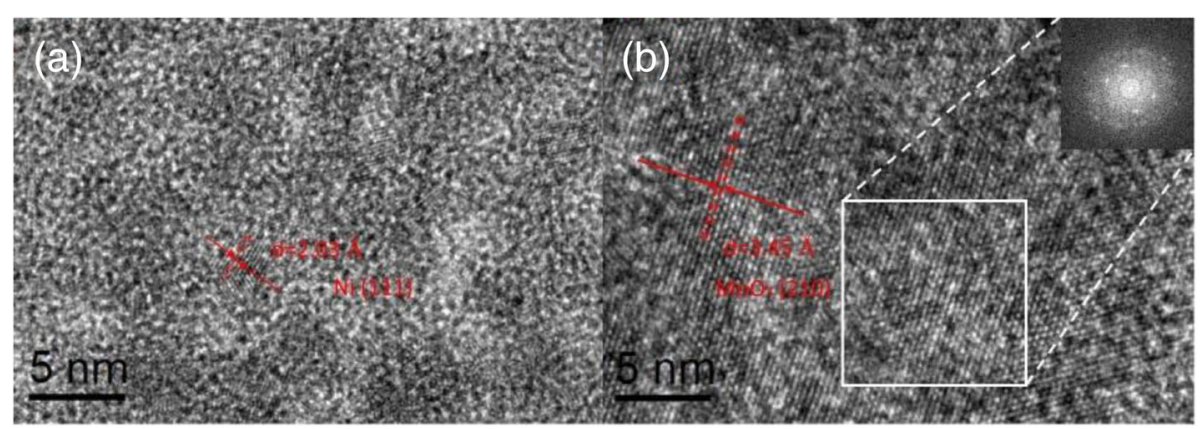

Fig. 10 HRTEM images of Ni particle and crystalline $\mathrm{MoO}_{3}$ particle on the NiMo15Al catalyst 
on the support $[40,41]$, in which the $\mathrm{Mo}_{7} \mathrm{O}_{24}{ }^{6-}$ intercalation modulate the particle size of Ni. And molybdenum oxide has already been partially transformed from amorphous to crystalline $\mathrm{MoO}_{3}$. The lattice spacing of the crystalline $\mathrm{MoO}_{3}$ is $3.45 \AA$, calculated by two-dimensional fast Fourier transform (FFT), which are in accordance with the plane (210) of $\mathrm{MoO}_{3}$. After reduction treatment, the lattice spacing of well dispersed embedded metal particles is $2.03 \AA$, consistent with that of the $\mathrm{Ni}$ (111) plane [41]. In summary, the high dispersion of small Ni nanoparticles is based on the pinning effect of Mo from $\mathrm{Mo}_{7} \mathrm{O}_{24}{ }^{6-}$ intercalated LDHs.

\section{Catalytic HDO of anisole}

The catalytic performance of HDO anisole derived from lignin over $\mathrm{NiMoAl}$ catalysts have been evaluated. All the experiments were carried out at least in duplicate and the result were well reproducible. The main products detected by GC-MS and GC are benzene (BEN) and cyclohexane (CHE). In addition, trace amount of phenol (PHE), cyclohexyl methyl ether (CME) and cyclohexanol (CHL) were also detected. Overall, the main reaction network and pathway of methoxy-rich compound anisole under the current conditions consist of three major classes of reactions: hydrogenation, hydrogenolysis and hydrodeoxygenation, as shown in Scheme 1. The main anisole hydrodeoxygenation reaction pathway may be divided into two steps: (i) the direct hydrodeoxygenation of anisole to benzene, (ii) the hydrogenation saturation of aromatic ring, resulting in the formation of cyclohexane. And small amounts of phenol, cyclohexanol and cyclohexyl methyl ether in the conversion of anisole are considered to be likely formed in sequential reactions but not the primary products.

The variation of the conversion of anisole and the major product distributions with $\mathrm{W} / \mathrm{F}$ over $\mathrm{NiAl}$, $\mathrm{NiMo}_{5} \mathrm{Al}, \mathrm{NiMo}_{15} \mathrm{Al}$ and $\mathrm{NiMo}_{30} \mathrm{Al}$ catalysts are shown in Fig. 12. Teerawit et al. [21] argued that $\mathrm{MoO}_{3}$ was an effective catalyst for the hydrodeoxygenation (HDO) of lignin-derived oxygenates to generate high yields of aromatic hydrocarbons without ring-saturated products and presented high selectivity for the $\mathrm{C}-\mathrm{O}$ bond cleavage under low $\mathrm{H}_{2}$ pressures ( $\leq 1 \mathrm{bar}$ ). Therefore, our experiments are performed under low- $\mathrm{H}_{2}$-pressure environment. With the increase of the active component in these catalysts, the anisole conversion gradually increases from 35.12 to $75.86 \%$ and then $93.65 \%$ within the W/F of $14.47 \mathrm{~min}$. The feedstock anisole was almost completely converted by $\mathrm{NiMo}_{30} \mathrm{Al}$ catalyst with the same W/F. It may be attributed to the increasing hydrodeoxygenation rate of anisole as the main conversion pathway, depending on the smaller Ni nanoparticles and more metallic catalytic sites possessing electron-acceptor properties [42]. The main products obtained from anisole are benzene and cyclohexane for all Ni-based catalysts. However, cyclohexyl methyl ether appears when the molybdenum species are not added into the catalyst. This indicates that there are the other parallel routes: the hydrogenation of the aromatic ring to form CME, which is converted then into $\mathrm{CHL}$, and finally hydro-deoxygenated to CHE. According to a study by Alonso [43], the hydrogenolysis activity by the $\mathrm{Ni}$

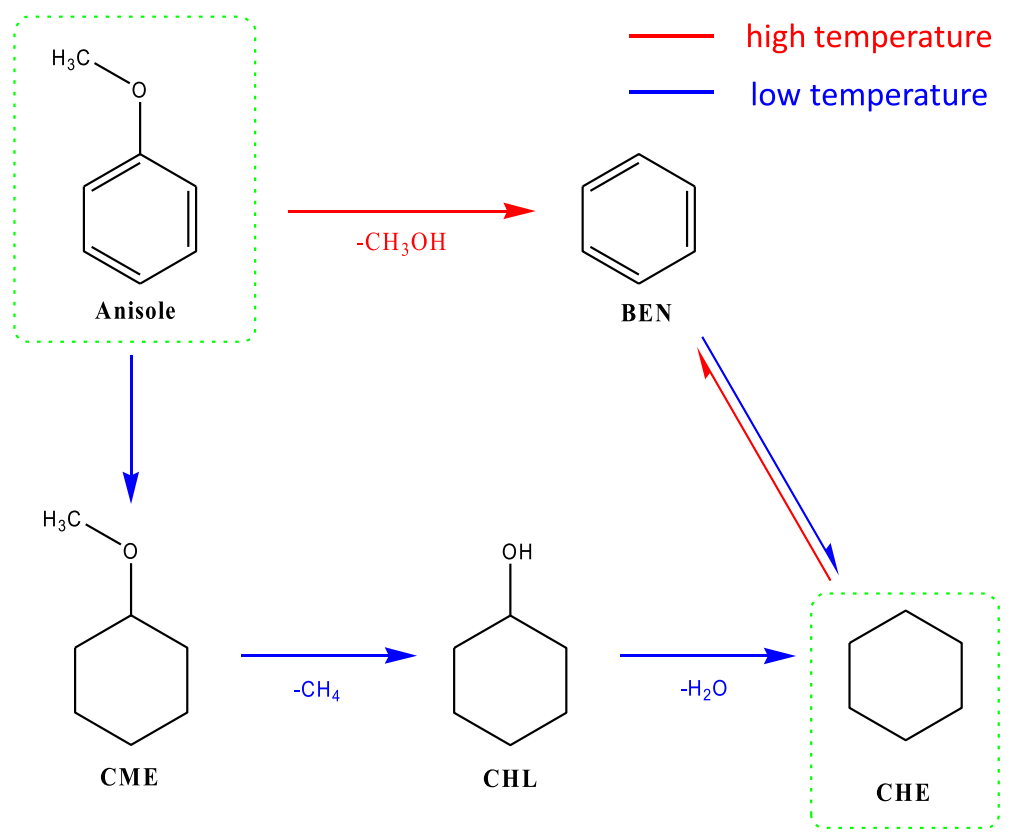

Scheme 1 The reaction network of anisole hydrodeoxygenation over the NiMoAl catalysts 

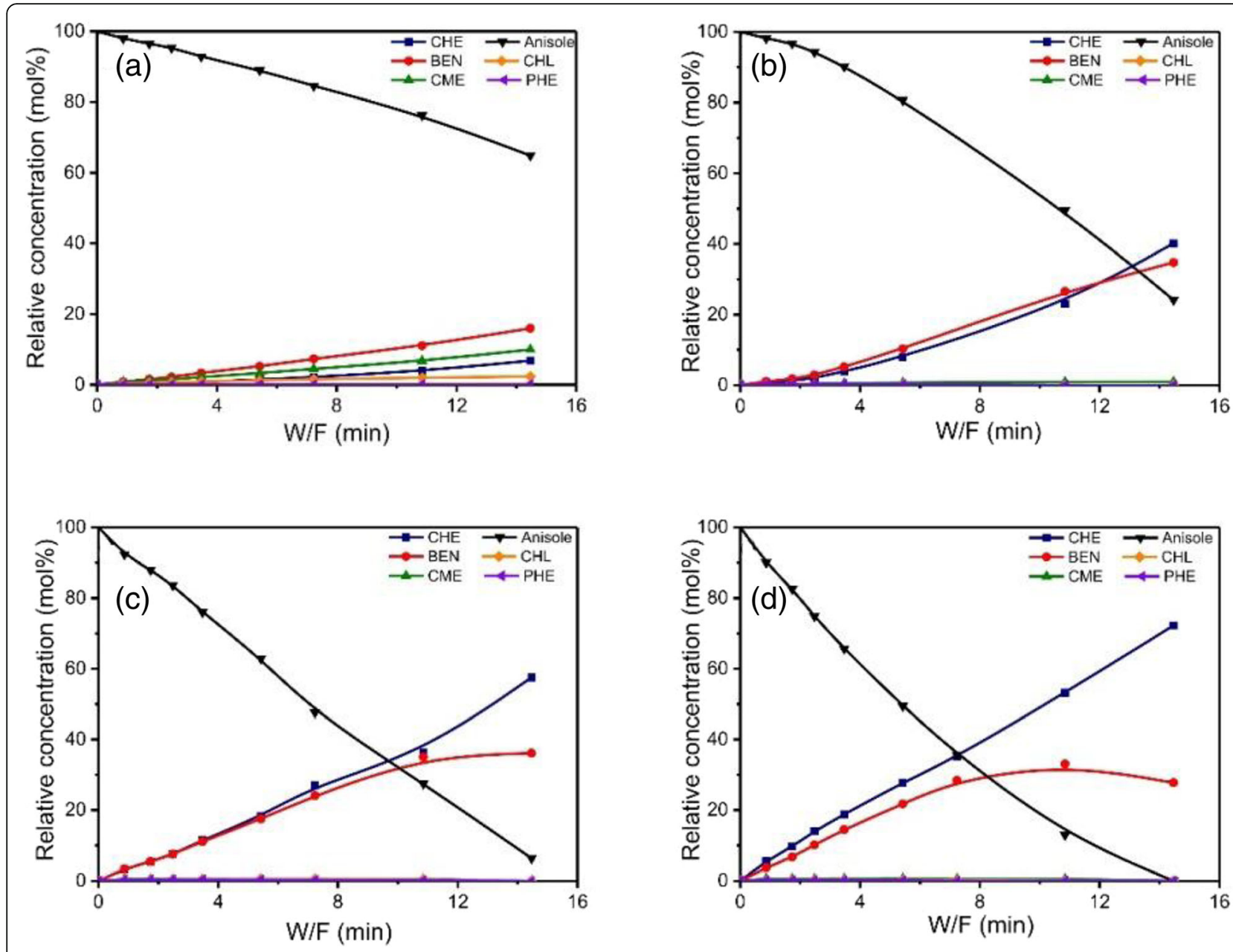

Fig. 11 Variation of the conversion of anisole and major product distributions with W/F over (a) NiAl catalyst, (b) NiMo5Al catalyst, (c) NiMo15Al catalyst, (d) NiMo30Al catalyst. Reaction condition: $280^{\circ} \mathrm{C}, 0.5 \mathrm{MPa} \mathrm{H}_{2}$, and the hydrogen-to-oil ( $\mathrm{H}_{2} / \mathrm{oil}$ ) ratio is 300

catalysts is low. CME is not easily converted into $\mathrm{CHE}$ by the $\mathrm{NiAl}$ catalyst, and the dissociation activity of $\mathrm{C}-\mathrm{O}$ bond would significantly be improved when molybdenum oxide is added, which is due to another new mechanism. The oxidation state of molybdenum exhibited a dramatic variation in the NiMoAl catalysts with different Mo contents. The higher Mo content in the catalysts favors the formation of $\mathrm{Mo}^{5+}$ and $\mathrm{Mo}^{4+}$ species. It proposed a reverse Mars-van Krevelen circulation mechanism. Once $\mathrm{Mo}^{5+}$ was formed, dehydroxylation led to reduction of two isolated $\mathrm{Mo}^{5+}$ to an intermediate $\mathrm{Mo}^{5+}$ pair. Interestingly, further hydrogenation of this $\mathrm{Mo}^{5+}$ pair led to a $\mathrm{Mo}^{6+}$ and $\mathrm{Mo}^{4+}$ species, and generated an oxygen vacancy site, which would result in the removal of the oxygen atom from the oxy-compound upon the adsorption on the vacancy site with concomitant regeneration of the vacancy with $\mathrm{H}_{2}$ to produce water. Therefore, $\mathrm{Mo}^{4+}$ is considered to be the deoxygenation active sites for the hydrodeoxygenation of small oxygenates. These results indicate that $\mathrm{Mo}^{4+}$ species are an adsorption site rather than an active site in the catalyst. In addition, the ratio of $\mathrm{BEN}$ to $\mathrm{CHE}$ decreases sharply from 10 to $0 \%$ with the increasing $\mathrm{Mo}^{4+}$ content at the W/F of $14.47 \mathrm{~min}$, which due to the synergistic effect between Ni particles and Mo species. And the $\mathrm{Mo}^{5+}$ species with $\mathrm{OH}$ groups are considered to be Brønsted acid sites. In this sense, the variation in the number of acid sites can be interpreted as due to the formation of $\mathrm{Mo}^{5+}$ species [44]. Therefore, the HDO of anisole continually improve with the enhanced Mo content.

Since the reaction temperature also plays a crucial role on the $\mathrm{C}-\mathrm{O}$ bond cleavage [15], the effect of temperature on the conversion of the feedstock anisole and the selectivity of products over $\mathrm{NiAl}$ and NiMo15Al catalysts has been investigated. The corresponding results are shown in Fig. 12. For NiAl catalyst, the anisole conversion only reaches up to $9 \%$ even at $220^{\circ} \mathrm{C}$, and the main target products are BEN, CHE, CME and CHL, respectively, with a selectivity of $4,19,56$ and $20 \%$. With the increase of reaction temperature to $300{ }^{\circ} \mathrm{C}$, the HDO 

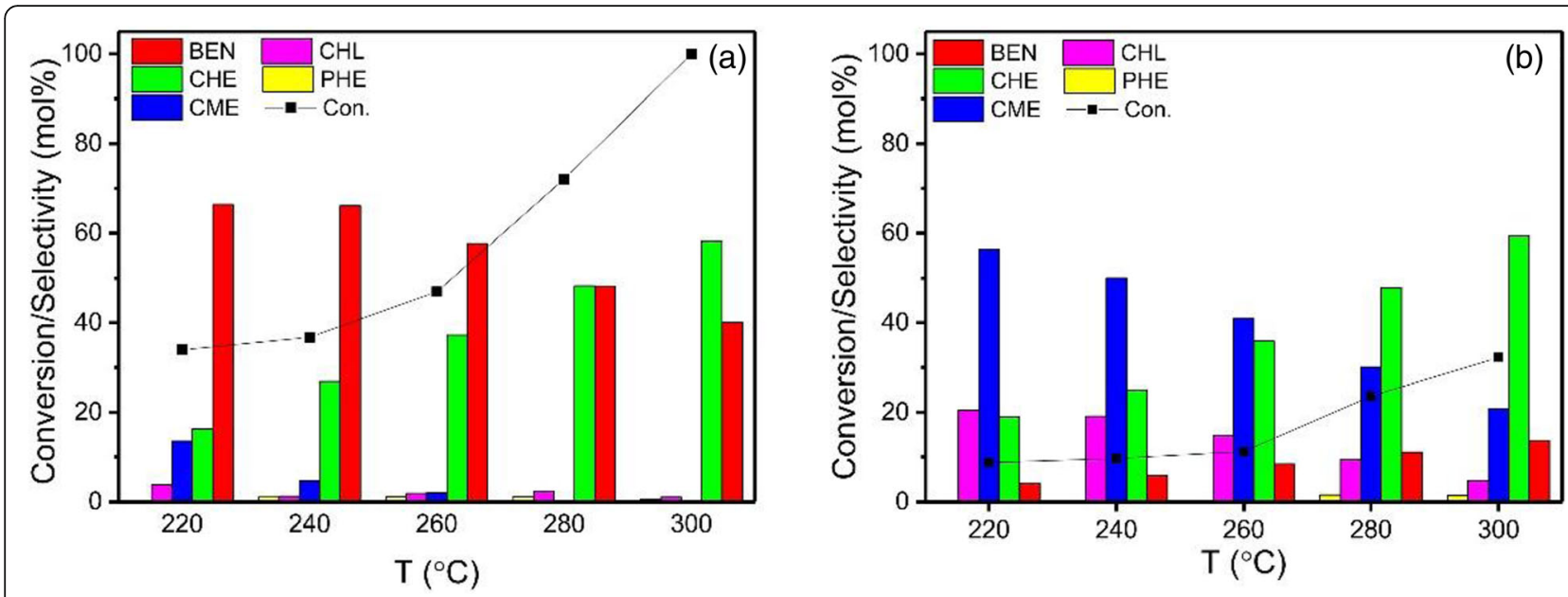

Fig. 12 Temperature dependence of DPE conversion and selectivity toward major products: (a) NiMo15Al catalyst, (b) NiAl catalyst. Reaction condition: W/F $=10.85 \mathrm{~min}, 0.5 \mathrm{MPa} \mathrm{H}_{2}$, and the hydrogen-to-oil $\left(\mathrm{H}_{2}\right.$ /oil) ratio is 300

activity of anisole obviously increases with an enhanced CHE selectivity to $60 \%$, but the direct hydrodeoxygenation pathway activity is just slightly increased and the selectivity of BEN reaches 14\%, proving that higher temperature can not only effectively promote the $\mathrm{Ni}$-catalyzed the hydrogenation and hydrogenolysis but also the direct hydrodeoxygenation reaction of anisole. On the other hand, the anisole conversion over NiAl catalyst is lower than that over NiMo15Al catalyst, which can be attributed to the relatively poor direct hydrodeoxygenation capacity derived from the larger nickel particles. When the temperature increased from $220^{\circ} \mathrm{C}$ to $300^{\circ} \mathrm{C}$, the $\mathrm{HDO}$ activity improve. Interestingly, the selectivity of BEN significantly decreases over the NiMo15Al catalyst with the temperature, which maybe because of the presence of another pathway to convert BEN to the other product and its activity improves as the increased temperature. And it is found that the curve shows the nonlinear variations with increasing temperature, the response to changes in conversion at high temperature zones is more sensitive than that at low temperature zones, suggesting that the catalytic mechanism is different at high and low temperature over the catalysts. There are three parallel pathways forming from anisole to cyclohexane over NiMoAl catalysts under the current conditions: (1) the $\mathrm{C}_{\text {aromatic }} \mathrm{O}$ bond cleavage with the formation of $\mathrm{BEN}$; (2) the hydrogenation of the aromatic ring to form CME, which is converted then into $\mathrm{CHL}$, and finally hydro-deoxygenated to CHE; (3) the reaction between BEN and CHE seems to be reversible.

Figure 13 shows the stability test of the NiMo15Al catalyst with the anisole conversions as a function of time-on-stream over $50 \mathrm{~h}$ at $280^{\circ} \mathrm{C}$, under $\mathrm{H}_{2}$ pressure of $0.5 \mathrm{MPa}$, with the W/F of $15.5 \mathrm{~min}$, which is adjusted to obtain a comparable initial conversion level. It is revealed that the conversion of anisole is initially $98 \%$ and gradually remained stable within the range of $88 \%$ after time on stream of $40 \mathrm{~h}$. It is obviously superior to normal Ni-based catalysts in the previous literatures [19], in which the deactivation is mainly induced by the agglomeration of Ni particles. A high density of small Ni nanoparticles with the pinning effect of Mo promotes the resistance to agglomeration. In addition, the selectivities of the main products are also summarized in Fig. 13. When the stability test is conducted after $45 \mathrm{~h}$, small oxygenates are detected to have been formed by the sequential reactions. This indicates that the HDO ability of the catalyst slightly decreases, which can be attributed to the decline of the oxygen vacancy sites. The oxygen vacancy sites are continually occupied by the oxygen atom from anisole but also unable to be completely reduced by $\mathrm{H}_{2}$. In other words, the reverse Mars-van Krevelen circulation cannot last induced by the low hydrogen pressure under a long time [45]. The selectivities of BEN and CHE are from 28.2 to $46 \%$ and from 71.7 to $53.4 \%$, respectively. Their respective changes presumably are due to a gradual and continuous modification of the catalyst surface by the oxygen-containing phenolic reactants during HDO, which has effect on the hydrogenation sites of benzene ring rather than the catalytic sites for aryl-oxygen bond cleavage, as similar as the previous reported findings [20].

In Summary, NiMoAl LDHs were successfully prepared by ion-exchange of NiAl-terephthalate LDHs with heptamolybdate anions, which exhibited good activity toward the removal of oxygen for the cleavage of anisole under the low hydrogen pressure. Upon calcination and subsequent reduction, catalysts with high dispersion of small $\mathrm{Ni}$ nanoparticles are 


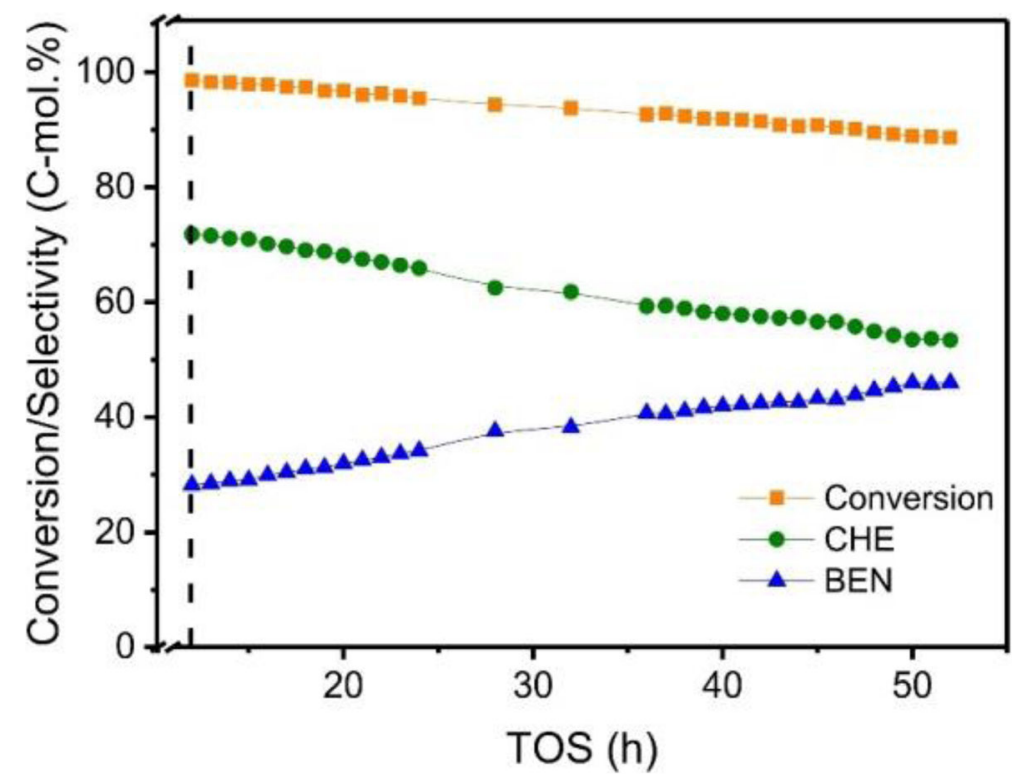

Fig. 13 Stability of the NiMo15Al catalyst in hydrodeoxygenation of anisole. Reaction condition: $280^{\circ} \mathrm{C}, 0.5 \mathrm{MPa} \mathrm{H}_{2}$, and W/F $=15.5 \mathrm{~min}$

obtained, based on the pinning effect of Mo around the metal particles. The reaction results indicate that the anisole conversion is rapidly improving with the addition of Mo species, which is owing to the existence of the reverse Mars-van Krevelen circulation. On the other hand, molybdenum species have been used to explore for the hydrodeoxygenation activity of small oxygenates with regard to the distribution of acid sites and the number of the oxygen vacancy site. Furthermore, the catalysts showed higher resistance to deactivation than the Ni-based catalysts, which can be broadly applied to other hydrodeoxygenation reactions.

\section{Methods}

1. Catalyst preparation and characterization

The preparation of the NiAl-terephthalate $\left(\mathrm{Ni}_{0.4} \mathrm{~A}-\right.$ $\left.\mathrm{l}_{0.6}(\mathrm{OH})_{2} \mathrm{TA}_{0.3} \cdot \mathrm{mH}_{2} \mathrm{O}\right) \mathrm{LDH}$ starting materials was described in detail [25]. Briefly, they were prepared by simultaneous dropwise addition to the de-ionized water, from an aqueous solution of the metal nitrates and another containing terephthalic acid dissolved in sodium hydroxide, so as to maintain the $\mathrm{pH}$ at $6.5 \pm$ 0.3. The precipitation was carried out at $80^{\circ} \mathrm{C}$ and the precipitate obtained was aged in the mother solution for $24 \mathrm{~h}$ at room temperature. The resulting solid (NiAl LDH) was recovered by vacuum filtration, thoroughly washed with de-ionized water to remove $\mathrm{Na}^{+}$ions until neutral $\mathrm{pH}$ was reached and finally the solid was dried at $100^{\circ} \mathrm{C}$ for $12 \mathrm{~h}$.

The terephthalate anion was exchanged with heptamolybdate by contacting $50 \mathrm{mg}$ of the NiAl LDH with different amount of $0.07 \mathrm{M}$ ammonium heptamolybdate (AHM) solution for $24 \mathrm{~h}$ in a closed Nalgene bottle heated to $80^{\circ} \mathrm{C}$, aiming to obtain different quantity of $\mathrm{Mo}_{7} \mathrm{O}_{24}{ }^{6-}$ ions intercalated LDHs. The exchanged material was recovered by the same process as NiAl LDH. The heptamolybdate-exchanged materials were named $\mathrm{NiMo}_{\mathrm{x}} \mathrm{Al} \mathrm{LDH}$, where $\mathrm{X}$ is equal to the percentages of Mo in the materials.

The amount of $\mathrm{Ni}, \mathrm{Al}$ and Mo was performed on inductively coupled plasma-optical emission spectroscopy (ICP-OES). Before analysis, a known amount of sample was dissolved with diluted nitromurlatic acid solution.

X-Ray powder diffraction (XRD) was carried out on D/MAX-2400 diffractometer with $\mathrm{Cu} \mathrm{K} \alpha_{1}$ radiation, $\lambda$ $=1.5418 \AA, 40 \mathrm{kV}, 40 \mathrm{~mA}$.

FTIR spectra were obtained in a Thermo Nicolet Nexus 410 instrument with the samples dispersed in 1:20 proportion in potassium bromide and pressed as wafers. Scans were performed between 4000 and $400 \mathrm{~cm}^{-1}$.

Temperature-programmed reduction experiments were performed in a stream of 10 vol.\% $\mathrm{H}_{2} / \mathrm{Ar}$ with a flow rate of $50 \mathrm{~cm}^{3} / \mathrm{min}$. The samples were heated up to a final temperature of $900^{\circ} \mathrm{C}$ at a rate of $10^{\circ} \mathrm{C} / \mathrm{min}$ and $\mathrm{H}_{2}$ consumption was monitored by a thermal conductivity detector.

In the temperature programmed desorption of ammonia $\left(\mathrm{NH}_{3}\right.$-TPD) experiments, the calcined materials were outgassed in $\mathrm{He}$ at $573 \mathrm{~K}$ for $2 \mathrm{~h}$, and then saturated at $373 \mathrm{~K}$ in a $10 \% \mathrm{NH}_{3} / \mathrm{He}$ stream $(50 \mathrm{~mL} / \mathrm{min})$ for $1 \mathrm{~h}$. After removing most of the weakly physisorbed $\mathrm{NH}_{3}$ by flowing $\mathrm{He}(50 \mathrm{~mL} / \mathrm{min})$, the chemisorbed $\mathrm{NH}_{3}$ was determined with a thermal conductivity detector (TCD) by 
heating at $10 \mathrm{~K} \mathrm{~min}^{-1}$ up to $973 \mathrm{~K}$ under the same flow of He.

Adsorption-desorption isotherms of the catalysts (approximately $0.10 \mathrm{~g}$ sample) were determined from $\mathrm{N}_{2}$ adsorption-desorption cycles performed on an autosorb IQ automated gas sorption analyzer. The specific surface areas and total volumes were calculated using the Brunauer-Emmett-Teller (BET) method, and the pore size distributions were obtained according to the adsorption branches by the Barrett-Joyner-Halenda (BJH) method.

The particle size dispersion of the samples was measured by electron micrographs. Before measurement, power samples were ground, suspended in ethanol, and dispersed by ultrasonic treatment. The obtained dispersion was transferred to a holey copper-grid-supported carbon film. The morphology and structural composition of the samples was examined by transmission electron microscopy (TEM), equipped with an energy-dispersive $\mathrm{X}$-ray (EDX) analyzer.

The morphology and structural composition of calcinated mixed-oxides were characterized and analyzed by tungsten filament scanning electron microscopy (SEM, Nova Nano SEM 450 from FEI Co.), equipped with an energy-dispersive X-ray (EDX) analyzer.

The XPS spectra were collected using an ESCALAB250 spectrometer with monochromatic $\mathrm{Al} \mathrm{K \alpha}$ radiation $(15 \mathrm{kV}, \mathrm{E}=1486.6 \mathrm{eV})$. The binding energy $(\mathrm{BE})$ values were referenced to the adventitious carbon ( $\mathrm{C} 1 \mathrm{~s}$ at $284.6 \mathrm{eV}$ ). A Shirley-type background was subtracted for Mo $3 \mathrm{~d}$ envelops, and the linear-type background was subtracted for Ni $2 p$ envelops.

\section{Catalytic HDO of Anisole}

To investigate the two types of $\mathrm{C}-\mathrm{O}$ bond cleavage reaction of ether compounds derived from pyrolysis oil, anisole is generally chosen as a test substrate. Catalytic HDO of anisole was conducted in a continuous flow fixed-bed reactor with a $9 \mathrm{~mm}$ stainless steel tube at 0.5 $\mathrm{MPa}$. Before use, the NiMoxAl LDH samples were calcined at $450^{\circ} \mathrm{C}$ in a 33 vol. $\% \mathrm{O}_{2} / \mathrm{He}$ stream $(40 \mathrm{~mL} / \mathrm{min})$ for $5 \mathrm{~h}$ (heating ramp of $1.5^{\circ} \mathrm{C} / \mathrm{min}$ ). The calcined NiMoxAl catalyst was placed into the fixed-bed reactor and reduced in situ by pure $\mathrm{H}_{2}(40 \mathrm{~mL} / \mathrm{min})$ at $450{ }^{\circ} \mathrm{C}$ for $2 \mathrm{~h}$ before the HDO experiments. Subsequently, the temperature of the reactor was adjusted to the desired reaction temperature $\left(200-280^{\circ} \mathrm{C}\right)$. The liquid reactants composed of $8 \mathrm{wt} . \%$ of anisole, $2 \mathrm{wt} . \%$ of $\mathrm{n}$-dodecane as internal standard for gas chromatography analysis, and $90 \mathrm{wt} . \%$ of $\mathrm{n}$-decane as inert solvent, were pumped into the reactor at different flow rates $(0.06-3.00 \mathrm{~mL} / \mathrm{min})$. Then, the experimental data were collected at different space times after the fresh catalyst reached steady state. The space time $(\mathrm{W} / \mathrm{F})$ is defined as the ratio of catalyst mass $(\mathrm{g})$ to substrate flow rate $(\mathrm{g} / \mathrm{min})$. The reaction products after being condense in a trap at room temperature were collected and analyzed by gas chromatograph (GC-7890F, FID, FFAP column, $30 \mathrm{~m} \times 0.32$ $\mathrm{mm} \times 0.5 \mu \mathrm{m})$ and identified by an Agilent $6890 \mathrm{~N} \mathrm{GC}$ (HP-5 MS capillary column, $30 \mathrm{~m} \times 0.25 \mathrm{~mm} \times 0.25 \mu \mathrm{m}$ ) with 5973 MSD. The conversion of anisole is defined as the number of $\mathrm{C}$ atoms reacted divided by the total number of $\mathrm{C}$ atoms in the reactant. The selectivity is defined as the number of $\mathrm{C}$ atoms in the product of interest divided by the total number of $\mathrm{C}$ atoms in all liquid products.

\begin{abstract}
Abbreviations
AHM: Ammonium heptamolybdate; BE: Binding energy; BEN: Benzene; BET: Brunauer-Emmett-Teller; BJH: Barrett-Joyner-Halenda;

CHE: Cyclohexane; CHL: Cyclohexanol; CME: Cyclohexyl methyl ether; EDX: Energy-dispersive X-ray; EDX: Energy-dispersive X-ray spectroscopy; FFT: Fast Fourier Transform; FTIR: Fourier Transform Infrared Spectroscopy; HDO: Hydrodeoxygenation; HRTEM: High-resolution transmission electron microscopy; LDHs: Layered double hydroxide; PHE: Phenol; PSD: Pore size distribution; SEM: Scanning electron microscopy; TCD: Thermal conductivity detector; TCD: Thermal Conductivity Detector; TEM: Transmission electron microscopy; TPD: Temperature programmed desorption; XPD: X-Ray powder diffraction spectroscopy; XPS: X-ray photoelectron spectroscopy
\end{abstract}

Acknowledgements

Not applicable.

Funding

This work was supported by the National Natural Science Foundation of China (21573031), The Program for Excellent Talents in Dalian City (2017RQ009), and The Fundamental Research Funds for the Central Universities (DUT18ZD211).

Availability of data and materials

All data generated or analyzed during this study are included in this published article.

\section{Authors' contributions}

C Li, X Zhang and X Chen are responsible for the synthesis and characterization of the catalysts and the catalytic performance evaluations. $C$ Tsang, Z Peng and C Liang are responsible for the conceptual design of the catalysts and the overseeing of the research project. All authors read and approved the final manuscript.

\section{Authors' information}

C Li is currently lecturer at Dalian University of Technology. X Zhang is master student at China University of Geosciences in Beijing. $X$ Chen is currently associate professor at Dalian University of Technology. Z Peng is professor at China University of Geosciences in Beijing. CW Tsang is currently academic staff at the Technological and Higher Education Institute of Hong Kong and the research manager at the Research Centre for Waste and Resource Management, Hong Kong. C Liang is Professor at Dalian University of Technology.

\section{Competing interests}

I confirm that I have read BioMed Central's guidance on competing interests and have included a statement in the manuscript indicating that none of the authors have any competing interests.

\section{Publisher's Note}

Springer Nature remains neutral with regard to jurisdictional claims in published maps and institutional affiliations.

\section{Author details}

${ }^{1}$ State Key Laboratory of Fine Chemicals, Laboratory of Advanced Materials and Catalytic Engineering, School of Chemical Engineering, Dalian University 
of Technology, Dalian 116024, People's Republic of China. ${ }^{2}$ School of Engineering and Technology, China University of Geosciences, Beijing 100083, People's Republic of China. ${ }^{3}$ Faculty of Science and Technology, Technological and Higher Education Institute of Hong Kong, Hong Kong, China.

Received: 25 February 2019 Accepted: 14 May 2019

Published online: 27 June 2019

\section{References}

1. Elliott DC. Historical developments in Hydroprocessing bio-oils. Energy Fuel. 2007;21:1792-815.

2. Czernik S, Bridgwater AV. Overview of applications of biomass fast pyrolysis oil. Energy Fuel. 2004;18(2):590-8.

3. Saidi M, Samimi F, Karimipourfard D, Nimmanwudipong T, Gates BC, Rahimpour MR. Upgrading of lignin-derived bio-oils by catalytic hydrodeoxygenation. Energy Environ Sci. 2014;7(1):103-29.

4. Mortensen PM, Grunwaldt JD, Jensen PA, Knudsen KG, Jensen AD. A review of catalytic upgrading of bio-oil to engine fuels. Appl Catal A Gen. 2011; 407(1-2):1-19.

5. Crossley S, Faria J, Shen M, Resasco DE. Solid nanoparticles that catalyze biofuel upgrade reactions at the water/oil Interface. Science. 2010;327:68-72.

6. Zhang Y, Cui B, Zhao C, Lin H, Li J. Co-Ni layered double hydroxides for water oxidation in neutral electrolyte. Phys Chem Chem Phys. 2013;15(19): 7363-9.

7. Li B, Zhao Y, Zhang S, Gao W, Wei M. Visible-light-responsive photocatalysts toward water oxidation based on NiTi-layered double hydroxide/reduced graphene oxide composite materials. ACS Appl Mater Interfaces. 2013;5(20): 10233-9.

8. Parida K, Mohapatra L. Recent progress in the development of carbonateintercalated $\mathrm{Zn} / \mathrm{Cr} \mathrm{LDH}$ as a novel photocatalyst for hydrogen evolution aimed at the utilization of solar light. Dalton Trans. 2012;41(4):1173-8.

9. Silva CG, Bouizi Y, Fornes V, Garcla H. Layered double hydroxides as highly efficient Photocatalysts for visible light oxygen generation from water. J Am Chem Soc. 2009:131:13833-9.

10. Fan G, Li F, Evans DG, Duan X. Catalytic applications of layered double hydroxides: recent advances and perspectives. Chem Soc Rev. 2014;43(20): 7040-66.

11. Zakzeski J, Bruijnincx PCA, Jongerius AL, Weckhuysen BM. The catalytic valorization of lignin for the production of renewable chemicals. Chem Rev. 2010;110(6):3552-99.

12. Runnebaum RC, Lobo-Lapidus RJ, Nimmanwudipong T, Block DE, Gates BC. Conversion of anisole catalyzed by platinum supported on alumina: the reaction network. Energy Fuel. 2011;25(10):4776-85.

13. González-Borja MÁ, Resasco DE. Anisole and Guaiacol Hydrodeoxygenation over monolithic Pt-Sn catalysts. Energy Fuel. 2011;25(9):4155-62.

14. Lee W-S, Wang Z, Wu RJ, Bhan A. Selective vapor-phase hydrodeoxygenation of anisole to benzene on molybdenum carbide catalysts. J Catal. 2014;319:44-53.

15. Jin S, Xiao Z, Li C, Chen X, Wang L, Xing J, Li W, Liang C. Catalytic hydrodeoxygenation of anisole as lignin model compound over supported nickel catalysts. Catal Today. 2014;234:125-32.

16. Jin S, Xiao Z, Chen X, Wang L, Guo J, Zhang M, Liang C. Cleavage of lignin-derived 4-O-5 aryl ethers over nickel nanoparticles supported on niobic acid-activated carbon composites. Ind Eng Chem Res. 2015;54(8): 2302-10.

17. Jin S, Chen X, Li C, Tsang C-W, Lafaye G, Liang C. Hydrodeoxygenation of lignin-derived Diaryl ethers to aromatics and alkanes using nickel on Zrdoped niobium phosphate. ChemistrySelect. 2016;1(15):4949-56.

18. Jin S, Guan W, Tsang C-W, Yan DYS, Chan C-Y, Liang C. Enhanced Hydroconversion of lignin-derived oxygen-containing compounds over bulk nickel catalysts though $\mathrm{Nb}_{2} \mathrm{O}_{5}$ modification. Catal Lett. 2017;147(8): 2215-24.

19. Zhang $X_{\text {, Chen }} X_{1}$, in $\mathrm{S}_{\text {, Peng }} \mathrm{Z}_{1}$ Liang $\mathrm{C}$. Ni/Al $\mathrm{O}_{3}$ catalysts derived from layered double hydroxide and their applications in Hydrodeoxygenation of anisole. ChemistrySelect. 2016;1 (3):577-84.

20. Chen $\mathrm{C}-J$, Lee W-S, Bhan $\mathrm{A} . \mathrm{Mo}_{2} \mathrm{C}$ catalyzed vapor phase hydrodeoxygenation of lignin-derived phenolic compound mixtures to aromatics under ambient pressure. Appl Catal A Gen. 2016;510:42-8.
21. Prasomsri T, Shetty M, Murugappan K, Román-Leshkov Y. Insights into the catalytic activity and surface modification of $\mathrm{MoO}_{3}$ during the hydrodeoxygenation of lignin-derived model compounds into aromatic hydrocarbons under low hydrogen pressures. Energy Environ Sci. 2014;7(8): 2660-9.

22. Kovanda F, Rojka T, Bezdička P, Jirátová K, Obalová L, Pacultová K, Bastl Z, Grygar T. Effect of hydrothermal treatment on properties of $\mathrm{Ni}$-Al layered double hydroxides and related mixed oxides. J Solid State Chem. 2009; 182(1):27-36.

23. Kooli F, Chisem IC, Vucelic M, Jones W. Synthesis and properties of terephthalate and benzoate intercalates of $\mathrm{mg}-\mathrm{Al}$ layered double hydroxides possessing varying layer charge. Chem Mater. 1996;8(8): 1969-77.

24. Vaysse C, Guerlou-Demourgues L, Demourgues A, Delmas C. Thermal behavior of Oxometalate (Mo, W)-intercalated layered double hydroxides: study of the grafting phenomenon. J Solid State Chem. 2002:167(1):59-72.

25. Arias S, Eon JG, San Gil RA, Licea YE, Palacio LA, Faro AC, Jr.: Synthesis and characterization of terephthalate-intercalated NiAl layered double hydroxides with high Al content. Dalton Trans 2013, 42(6):2084-2093.

26. Arias $\mathrm{S}$, Licea YE, Palacio LA, Faro AC. Unsupported NiMoAl hydrotreating catalysts prepared from NiAl-terephthalate hydrotalcites exchanged with heptamolybdate. Catal Today. 2013;213:198-205.

27. Madeira LM, Portela MF, Mazzocchia C. Nickel Molybdate catalysts and their use in the selective oxidation of hydrocarbons. Catal Rev. 2004:46(1):53-110.

28. Medema J, Stam CV, VHJd B, Konings AJA, Koningsberger DC. Raman spectroscopic study of co-Mo/Y- $-\mathrm{Al}_{2} \mathrm{O}_{3}$ catalysts. J Catal. 1978;53:386-400.

29. Imamura S, Sasaki H, Shono M, Kanai H. Structure of molybdenum supported on $a^{-}, \gamma^{-}$, and $X$-Aluminas in relation to its epoxidation activity. J Catal. 1998:177:72-81.

30. Palmer $S$, Frost R, Nguyen T. Hydrotalcites and their role in coordination of anions in Bayer liquors: anion binding in layered double hydroxides. Coord Chem Rev. 2009;253(1-2):250-67.

31. Chen N, Gong S, Qian EW. Effect of reduction temperature of $\mathrm{NiMoO}_{3-x} /$ SAPO-11 on its catalytic activity in hydrodeoxygenation of methyl laurate. Appl Catal B Environ. 2015;174-175:253-63.

32. Zhao M-Q, Zhang Q, Zhang W, Huang J-Q, Zhang Y, Su DS, Wei F. Embedded high density metal nanoparticles with extraordinary thermal stability derived from guest-host mediated layered double hydroxides. J Am Chem Soc. 2010;132(42):14739-41.

33. Klimova T, Lizama L, Amezcua JC, Roquero P, Terrés E, Navarrete J, Domínguez JM. New NiMo catalysts supported on Al-containing SBA-16 for 4,6-DMDBT hydrodesulfurization. Catal Today. 2004;98(1-2):141-50.

34. Mojet BL, Miller JT, Ramaker DE, Koningsberger DC. A new model describing the metal-support interaction in Noble metal catalysts. J Catal. 1999;186:373-86.

35. Barath F, Turki M, Keller V, Maire G. Catalytic activity of reduced $\mathrm{MoO}_{3} / \mathrm{a}$ $\mathrm{Al}_{2} \mathrm{O}_{3}$ for hexanes reforming I. preparation, characterization, and X-ray photoelectron spectroscopy studies. J Catal. 1999;185:1-11.

36. Oliveros I, Zurita MJP, Scott C, Goldwasser MR, Goldwasser J, Rondon S, Houalla $\mathrm{M}$, Hercules DM. The isomerization of cyclopropane over reduced Molybdena-alumina catalysts. J Catal. 1997;171:485-9.

37. Shetty M, Murugappan K, Prasomsri T, Green WH, Román-Leshkov Y. Reactivity and stability investigation of supported molybdenum oxide catalysts for the hydrodeoxygenation (HDO) of m-cresol. J Catal. 2015; 331:86-97.

38. Kitano T, Okazaki S, Shishido T, Teramura K, Tanaka T. Brønsted acid generation of alumina-supported molybdenum oxide calcined at high temperatures: characterization by acid-catalyzed reactions and spectroscopic methods. J Mol Catal A Chem. 2013;371:21-8.

39. Selvaraj M, Shanthi K, Maheswari R, Ramanathan A. Hydrodeoxygenation of Guaiacol over $\mathrm{MoO}_{3}-\mathrm{NiO} /$ mesoporous silicates: effect of incorporated heteroatom. Energy Fuel. 2014;28(4):2598-607.

40. Whiffen VML, Smith KJ. Hydrodeoxygenation of 4-Methylphenol over unsupported MoP, $\mathrm{MoS}_{2}$, and $\mathrm{MoO}_{x}$ catalysts. Energy Fuel. 2010;24(9): 4728-37.

41. Richardson JT, Lei M, Turk B, Forster K, Twigg MV. Reduction of model steam reforming catalysts: $\mathrm{NiO} / \mathrm{a}-\mathrm{Al}_{2} \mathrm{O}_{3}$. Appl Catal A Gen. 1994;110:217-37.

42. Gevert BS, Otterstedt J-E, Massoth FE. Kinetics of the HDO of methylsubstituted phenols. Appl Catal. 1987;31:119-31. 
43. Alonso DM, Wettstein SG, Dumesic JA. Bimetallic catalysts for upgrading of biomass to fuels and chemicals. Chem Soc Rev. 2012;41(24):8075-98.

44. Moberg DR, Thibodeau TJ, Amar FG, Frederick BG. Mechanism of

Hydrodeoxygenation of Acrolein on a cluster model of $\mathrm{MoO}_{3}$. J Phys Chem C. 2010;114(32):13782-95.

45. Mars $P$, van Krevelen DW. Oxidations carried out by means of vanadium oxide catalysts. Chem Eng Sci. 1954;3:41-59.

Ready to submit your research? Choose BMC and benefit from:

- fast, convenient online submission

- thorough peer review by experienced researchers in your field

- rapid publication on acceptance

- support for research data, including large and complex data types

- gold Open Access which fosters wider collaboration and increased citations

- maximum visibility for your research: over $100 \mathrm{M}$ website views per year

At $\mathrm{BMC}$, research is always in progress.

Learn more biomedcentral.com/submissions 